\title{
Covalent Organic Frameworks: Promising Materials as Heterogeneous Catalysts for C-C Bond Formations
}

\author{
Dongge Ma ${ }^{1} * \mathbb{C}^{\mathbb{D}}$, Yi Wang ${ }^{1}$, Anan Liu ${ }^{2}$, Shuhong $\mathrm{Li}^{1, *}$, Chichong $\mathrm{Lu}^{1}$ and Chuncheng Chen ${ }^{3}$ \\ 1 School of Science, Beijing Technology and Business University, Beijing 100048, China; \\ wangyi_ii@163.com (Y.W.); luchichong@btbu.edu.cn (C.L.) \\ 2 Basic Experimental Center for Natural Science, University of Science and Technology Beijing, Beijing 100083, \\ China; liuanan@ustb.edu.cn \\ 3 Key Laboratory of Photochemistry, Beijing National Laboratory for Molecular Sciences, Institute of \\ Chemistry, Chinese Academy of Sciences, Beijing 100190, China; ccchen@iccas.ac.cn \\ * Correspondence: madongge@btbu.edu.cn (D.M.); lish@th.btbu.edu.cn (S.L.); \\ Tel.: +86-10-6898-5573 (D.M. \& S.L.)
}

Received: 28 August 2018; Accepted: 15 September 2018; Published: 19 September 2018

\begin{abstract}
Covalent organic frameworks (COFs) are defined as highly porous and crystalline polymers, constructed and connected via covalent bonds, extending in two- or three-dimension. Compared with other porous materials such as zeolite and active carbon, the versatile and alternative constituent elements, chemical bonding types and characteristics of ordered skeleton and pore, enable the rising large family of $\mathrm{COFs}$ more available to diverse applications including gas separation and storage, optoelectronics, proton conduction, energy storage and in particular, catalysis. As the representative candidate of next-generation catalysis materials, because of their large surface area, accessible and size-tunable open nano-pores, COFs materials are suitable for incorporating external useful active ingredients such as ligands, complexes, even metal nanoparticles deposition and substrate diffusion. These advantages make it capable to catalyze a variety of useful organic reactions such as important $\mathrm{C}-\mathrm{C}$ bond formations. By appropriate pore-engineering in $\mathrm{COFs}$ materials, even enantioselective asymmetric $\mathrm{C}-\mathrm{C}$ bond formations could be realized with excellent yield and $e e$ value in much shorter reaction time compared with their monomer and oligomer analogues. This review will mainly introduce and discuss the paragon examples of COFs materials for application in C-C bond formation reactions for the organic synthetic purpose.
\end{abstract}

Keywords: covalent organic frameworks; heterogeneous catalysts; organic synthesis; C-C bond formation

\section{Introduction}

Nanoporous materials possess extremely large surface areas, ordered pore channel structure, tunable active sites and functional groups [1-20]. These properties rendered them as pivotal nano-platforms for various applications such as adsorption and separation [21-29], energy storage [30-49], proton conduction [47,48,50-52] and catalysis [6,53-61]. In particular, as the workhorse of current synthetic chemistry, catalytic reactions as well as catalysts are faced with the challenge of updating the use of more green, earth-rich and high-efficient materials and advanced assembles to win the sustainable development. These new-type artificial nano-porous materials have been constantly developed and applied as pivotal catalysts for both fine-chemical and petrochemical industry for several decades [62-66]. After these 70 years exploration, the domain of nanoporous material has been greatly extended from traditional inorganic mesoporous materials zeolites [4,67-69] to organic-inorganic hybrid materials coordination polymer [70-76] and metal-organic-frameworks (MOFs) [2,77-85]. Although a number of highly porous organic 
polymers with considerably large surface area have been designed and synthesized such as hyper-crosslinked polymers [86-91], polymers with intrinsic microporosity [92-100], conjugated microporous polymers [101-105], the linking chemistry totally relied on kinetically controlled irreversible coupling reactions. The irreversibility brought about the poor self-healing ability of these porous materials, which leaded to disordered pore and skeleton structure, and the formation of non-separable oligomers. The presence of structure disorders and oligomers severely limited their applications in catalysis. Organic porous materials which were conformed of long-range order structure and showed good crystallinity were severely desired.

Since the first seminal work by Omar Yaghi in 2005 [106], covalent organic frameworks (COFs) materials have been focused as a hot research field, explored and developed rapidly with great progress [22,23,107-110]. Compared with inorganic zeolites and silica porous materials, COFs materials possess higher porosity, tunable and larger pore size. These properties would facilitate the diffusion of the reactants and the desorption of the products. In this way, higher selectivity and yield can be obtained. Moreover, COFs materials usually own ultrahigh theoretical specific surface area and high chemical stability. These advantages render them very ideal heterogeneous catalyst for organic synthetic transformations. However, COFs materials are not perfect. They have some intrinsic disadvantages. Commonly, COFs materials show poorer crystallinity with more disordered and impure structures in comparison with zeolites and MOFs materials. And it is very difficult to obtain COF single crystal. The poor crystallinity and the difficulty in obtaining single crystalline COF all lead to the difficulty in confirming the accurate COF structure and the limitation in synthetic applications. Although COFs have ultrahigh theoretical specific surface area, it is very difficult to get high experimental specific surface area as MOFs due to the poorer crystallinity. And since the main skeleton structure of COFs materials is conformed of organic unit, the thermal stability could not be as high as inorganic crystalline zeolites materials. The major difference between COFs and other porous organic polymer materials is (i) that the key synthesizing reactions in the preparation of COFs materials are reversible. This endowed COFs forming process with high self-healing ability. And due to the self-healing and error-checking mechanism of the reversible and thermodynamically-controlled dynamic covalent chemistry, COFs material can form definitively long-range ordered crystalline structure [110]. The connection manner of organic building blocks in COFs is atomically precise 2D or 3D [107] extended polymeric structure with sufficient long-range order and retained crystallinity without compromising porosity; (ii) since the elements constitute COFs materials are all light elements $(\mathrm{C}, \mathrm{H}, \mathrm{B}, \mathrm{N}, \mathrm{O}, \mathrm{Si})$, the density of $\mathrm{COFs}$ are usually lower than other ordered micro- and mesoporous frameworks such as MOFs. Owing to the relative heavy metal ions as well their powerful hydrolysis nature, most MOFs materials lose their ordered structure and diffraction peaks in X-ray diffraction characterization experiments simply after contacting aqueous condition or even humid air. However, compared with its MOFs counterpart, many kinds of COFs display excellent stability in water, organic solvents and even extremely basic, acidic, reductive and oxidative condition [111-117]. Even long-time immersing in these harsh conditions does not deteriorate its long-ordered structure and crystallinity. This extraordinary stability is mainly attributed to that the skeleton structure was metal-free and constructed from strong covalent bonds, which possess much greater bond-dissociation-energy than coordinative bond in MOFs structure; (iii) moreover, the hydrogen bonding and $\pi-\pi$ stacking interaction in COFs further strengthen the COFs skeleton and pore structure and prevent them from destruction by collective solvation, hydrolysis and redox presses in most catalytic cases; (iv) finally, and more important, intrinsic COFs materials themselves in fact have seldom active sites and/or catalytic activity as general regular catalysts to trigger $\mathrm{C}-\mathrm{H}$ or $\mathrm{C}-\mathrm{X}(\mathrm{X}=\mathrm{Cl}, \mathrm{Br}, \mathrm{I}, \mathrm{O}, \mathrm{S}$, etc.) transformation for synthetic purpose. Therefore, appropriate active components such as $\mathrm{Pd}, \mathrm{Ir}, \mathrm{Ru}$, etc. are often incorporated into the special pore or channel of COFs as catalytic active sites or groups [118]. In order to keep either the activity towards substrates and entire selectivity of reactions or COFs structure long-rang order, such an integrating of other active components with COFs pore structure through 
binding or coordination has raised a lot of interesting impregnation model and topological structures, which greatly broadens the range of transition- metal catalysis application [115].

According to the organic building block's extending dimension, COFs are divided into two categories, 2D and 3D COFs. In 2D COFs, the covalent bond connects the organic building block in sheets, while the interlayer connection interaction can be $\pi-\pi$ stacking and Van-der-Waals force (see Figure 1a). 3D COFs stretch and extend the framework in space with $\mathrm{sp}^{3}$ tetrahedral carbon or silane building blocks with covalent bond connection in every dimension (see Figure 1b). Due to the interlayer $\pi-\pi$ stacking and intralayer rigid aromatic motifs, $2 \mathrm{D}$ COFs commonly form columnar structure with linear 1D nano-pores channel penetrating the whole COF materials. The ordered column and direct penetrating open-pores permit the precise assembly of donor-acceptor structure in a highly ordered manner. This property renders 2D COFs much potential applications in functional optoelectronics such as sensing [119,120], luminescent [121,122], photoconductive [123-125], photovoltaic [124,126-128] and photocatalytic materials [129-133]. In comparison, 3D COFs possess highly developed porous structure in space and with their long-range order, i.e., crystallinity $[107,134]$. Moreover, 3D COFs enjoy the present record highest surface area (larger than $4000 \mathrm{~m}^{2} / \mathrm{g}$ ) and lowest density $\left(0.17 \mathrm{~g} / \mathrm{cm}^{3}\right)$ among all COF materials, which is especially attractive as catalyst candidates [21,22,135-137].
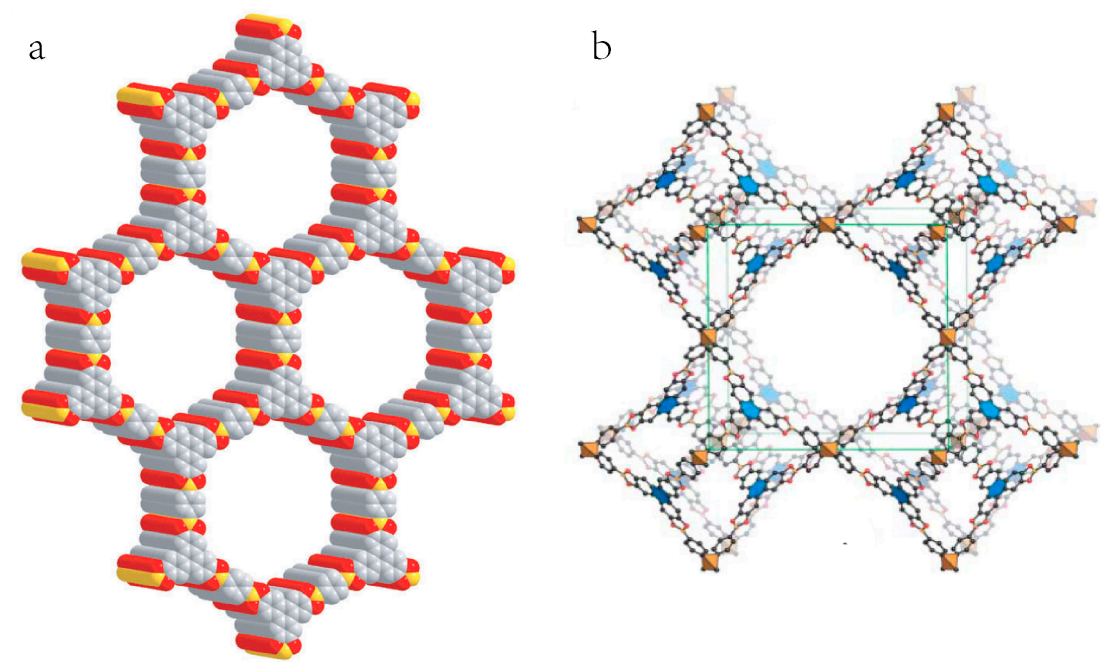

Figure 1. The structure of a typical 2D COF (a) and 3D COF (b) Hydrogen atoms are omitted for clarity. Carbon, boron, and oxygen atoms are represented as gray, orange, and red spheres, respectively, polyhedron in orange and triangle in blue, respectively. Reprinted with permission from [106], Copyright 2005, Science and [107] Copyright 2007, Science.

There appeared several detailed excellent reviews covering COFs materials' applications in $\mathrm{CO}_{2}$ capture [108,138-140], electrocatalysis [141,142], photocatalytic visible-light hydrogen evolution etc., $[132,133,143]$. As one important branch of catalysis, 2D and 3D COFs materials are stepping into the catalyzed organic synthesis chemistry area. Some important organic reactions including oxidation [144-158], reduction [117,159,160], C-C and C-heteroatom coupling reactions have been successfully realized by COFs catalysis for a diversity of synthetic purpose [161,162]. Even very challenging asymmetric organic synthesis have been accomplished by COFs materials modified with enantioselective organocatalysts [163]. Compared with common heterogeneous transition metal-catalyzed organic synthesis [164-168], COFs catalysis has displayed great flexibility and freedom to fit the various difficult organic synthesis task with high standard and high demand. Despite the fact that there are a few reviews on the application of COFs materials as heterogeneous catalysts in the organic synthesis, $[163,169,170]$ there has remained not yet review focused on selective C-C formation reaction catalyzed by $\mathrm{COF}$ materials. In this article, we review recent advances in the utilization of COFs as catalysts to realize the most meaningful organic transformations, namely, C-C coupling reaction 
for $\mathrm{C}-\mathrm{C}$ bond formation reactions. A series of important $\mathrm{C}-\mathrm{C}$ coupling examples mediated by $\mathrm{COFs}$ catalysts are summarized for the synthesis purpose in analogues to Heck, Suzuki-Miyaura, Sonogashira cross-coupling, carbon-centered nucleophilic addition and cross-dehydrogenative couplings (CDC) with an emphasis on understanding the conversion mechanism. Especially we provide an outlook on the current challenges and promising opportunities in this burgeoning COFs application area. We believe that the advanced catalytic transformation strategies based on COFs catalysts will open up a new avenue to supplement the shortages of other transition-metal catalysis in C-C bond synthesis applications.

\section{COFs Application as Heterogeneous Catalysis for C-C Bonds Coupling Reactions}

Catalytic C-C coupling strategy is always the core of current organic synthesis chemistry field. $\sim 85 \%$ synthesis projects in fine chemical production, pharmaceutical synthesis, agricultural chemicals and household chemicals etc. are involved in catalyzed C-C coupling movements. Now the catalytic $\mathrm{C}-\mathrm{C}$ bond formation reactions often resort to homogeneous transition-metal complexes catalysis system such as the famous Pd-catalyzed Suzuki-Miyaura and Heck cross-coupling reactions [171]. The key of these success systems is that these d-block transition-metal complexes commonly have empty $\pi^{*}$ anti-bonding orbital for $\pi$ back-bonding and electron pair for coordination to $\mathrm{sp}^{2}$ or sp hybrid carbon-carbon multiple bond [172]. Moreover, these transition-metal centers are very adapted to the oxidative addition and reductive elimination. The low-valent transition-metals are stabilized by a variety of ligands bearing lone-pair electrons and $\pi^{*}$ anti-bonding orbit. Thus, it is very facile to choose a number of different chiral ligand to render the transition-metal complex asymmetric activity [173]. These chiral organometallic compounds are often very powerful catalyst for asymmetric C-C coupling reactions. The realization of these asymmetric cross-coupling has greatly enlarged the application scopes of transition-metal catalyzed reactions [174]. Although COFs are very novel materials with short history, the researches on COFs materials are evolving extremely rapid. More and more research articles have revealed that COFs materials possessed many unique properties, significantly differentiating from organic-inorganic hybrid materials such as MOFs [6]. Why chemists favor COFs materials for the specific catalytic $\mathrm{C}-\mathrm{C}$ coupling reactions? The reasons can be summarized as the following three points. (i) From the prospect of industrial applications, Pd-based homogeneous catalyst has the intrinsic limitation. Especially for drug synthesis, the bio-toxicity of the noble-metal residue has long-time been worried and criticized by the public. And the efficiency of metal separation is unsatisfactory. Moreover, the cost for separation comprises a large portion of the total cost in drug production. Thus, developing heterogeneous catalysis, especially encapsulating the catalytically active species such as $\mathrm{Pd}$, etc. into the pore space of porous materials like COFs with uncompromising catalytic efficiency will solve the issue of separating the toxic metal residues. (ii) From the prospect of catalytic efficiency, which is the core issue in catalysis, after binding metal active species, the metal catalytic center is confined by COFs pore. On one hand, this will increase the difficulty of substrate diffusing and approaching the catalytic sites and the products leaving the catalytic center, which would decrease the TOF (turn-over-frequency). However, on another hand, by the fine-tuning of COFs constituents and pore structures, the COFs will repulse solvent molecules and accelerate substrate adsorption and products desorption. Compared with homogeneous catalyst, this acceleration will greatly increase the efficiency and selectivity. Certainly, realizing this point is very challenging. However, this is just the most attractive property of COFs materials, that is, to search the optimal COFs constituent and pore structure. On one hand, this optimized COFs constituent and pore structure will settle and accommodate metal catalytic center to exert its catalytic ability of oxidative addition and reductive elimination to the maximum. On the other hand, this will fine-tune the selectivity of substrate adsorption and product desorption rate. Most of the following examples in this review are the breakthroughs and proceedings in these prospects. (iii) Compared with other 2D or 3D pore-structure materials, such as the most similar MOFs counterparts, the advantage of COFs in catalyzing C-C coupling reactions is the absence of another external transition-metal center (metal in MOF) to influence 
the encapsulated Pd catalysis, which avoids as-induced side-reactions. (iv) As the above-mentioned, the stability to aqueous, acidic, basic and organic solvents renders COFs very inert to be solvated and decomposed. Certainly, due to the short history of COFs materials, its applications and adaptions for $\mathrm{C}-\mathrm{C}$ coupling reactions require further development and improvement. Even so, the currently reported examples, i.e., the following recommended paragon ones, have already displayed the bright prospects for significant application and development.

We would divide the following examples and discussion according to the $\mathrm{C}-\mathrm{C}$ coupling reaction types and recommend the following several typical COFs catalyst synthesis and catalytic performance.

\subsection{Suzuki-Miyaura Reaction}

In 2011, Wang et al. reported the first example of COF material for catalysis application [118]. They synthesized a imine-linked 2D COF material (COF-LZU1) by heating 1,3,5-triformylbenzene and 1,4-diaminobenzene in 1,4-dioxane/aqueous acetic acid solution in anaerobic condition after liquid nitrogen flash-frozen, evacuation and flame-sealing treatment (See Figure 2). The as-synthesized COF materials displayed a two-dimensional layered-sheet structure, with eclipsed nitrogen atoms in adjacent layers a distance of $\sim 3.7 \AA$. This imine-linked COF-LZU1 material demonstrated high coordination affinity to $\mathrm{Pd}(\mathrm{OAc})_{2}$ due to nitrogen-palladium strong interaction. Only by simple impregnation, $\mathrm{Pd}(\mathrm{OAc})_{2}$ was effectively incorporated into COF-LZU1 channels and pores. This metal incorporation did not greatly eliminate $\mathrm{COF}$ material's long-ordered structure although reduced the intensity of powder X-ray diffraction (PXRD) and Brunauer-Emmett-Teller (BET) surface area in a certain degree. The Pd-incorporated COF material demonstrated much enhanced catalytic activity, shorter reaction time and lower catalyst load than $\mathrm{Pd}(\mathrm{OAc})_{2}$ and its $\mathrm{Pd}-\mathrm{MOF}$ analogues in typical Suzuki-Miyaura cross-coupling reaction. Moreover, this COF material did not lose its catalytic activity at all even after four cycles reuse. This superior catalytic activity and stability after reutilization rendered it very promising catalyst for classical Suzuki-Miyaura reactions.

In 2015, Jiang et al. reported that a porphyrin-based $\mathrm{H}_{2} \mathrm{P}-\mathrm{Bph}-\mathrm{COF}$ material could incorporate $\mathrm{Pd}(\mathrm{OAc})_{2}$ species to efficiently catalyze a Suzuki reaction with excellent yields ranging from 97.1-98.5\% [175]. This COF material was synthesized via the condensation reaction between 5,10,15,20-tetra( $p$-amino-phenyl) porphyrin and 4,4'-biphenyldialdehyde in a EtOH/mesitylene/acetic acid aqueous solution at $120{ }^{\circ} \mathrm{C}$ for 3 days in vacuum (See Figure 3.) The as-formed COF material was nitrogen-rich due to the porphyrin unit's tetrapyrrole group and imine $\mathrm{C}=\mathrm{N}$ bonds. These excess nitrogen groups aced as effective docking sites for $\mathrm{Pd}(\mathrm{OAc})_{2}$ complexation. Solid State (SS)- ${ }^{13} \mathrm{C}-\mathrm{NMR}$ (nuclear-magnetic-resonance), FT-IR (Fourier Transform infrared spectroscopy), XPS (X-ray photoelectron spectroscopy) and ICP-AES (Inductively Coupled Plasma-Atomic Emission Spectroscopy) characterizations all confirmed the inclusion of $\mathrm{Pd}(\mathrm{OAc})_{2}$. The porosity and crystallinity decreased in a certain degree after Pd incorporation. This $\mathrm{Pd}-\mathrm{H}_{2} \mathrm{P}-\mathrm{COF}$ showed superior catalytic activity for Suzuki cross-coupling reactions for a variety of bromoarenes and phenylboronic acid, forming biphenyl derivatives with yields ranging from $97.1-98.5 \%$ surpassing its $\mathrm{Pd}-\mathrm{MOF}$ and $\mathrm{Pd} / \mathrm{C}$ counterparts (the yield of 4-methoxybiphenyl product was $65.0 \%$, while the yield for Pd/MOF was $84.1 \%$ [176]). This report was inspiring and encouraging since the authors showed that porphyrin-based catalyst could not only promote the radical or carbene-based oxidation, but also accelerate the cross-coupling reaction by incorporating $\mathrm{Pd}$ complex in to a COF support. 


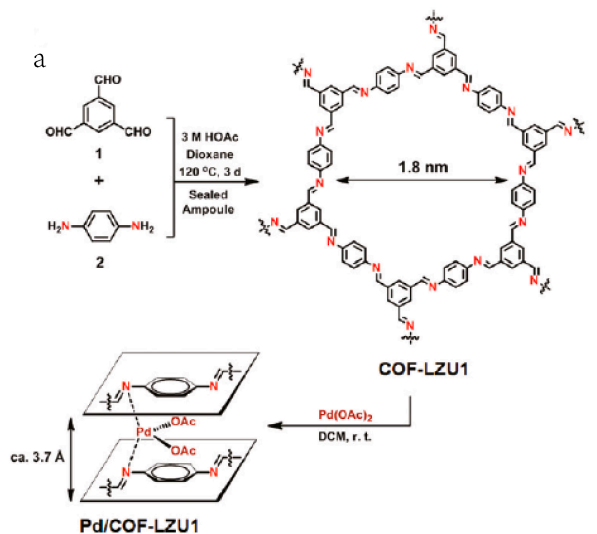

b

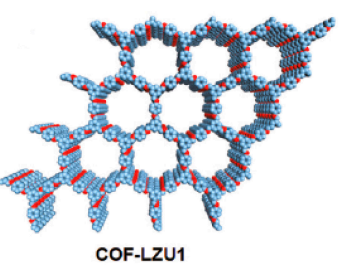

COF-LZU1
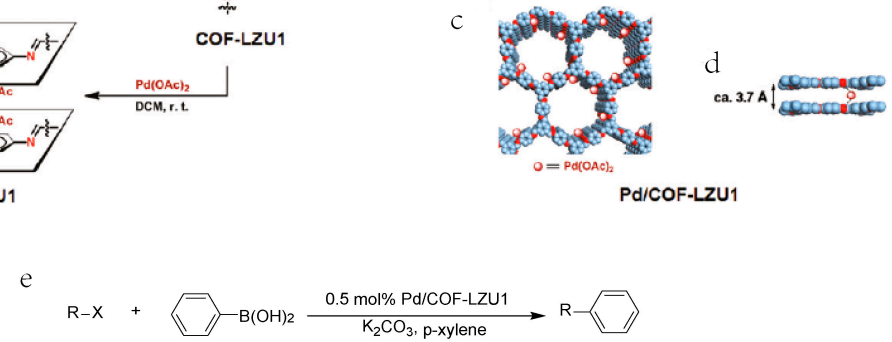

\begin{tabular}{ccccc} 
Entry & $\mathrm{X}$ & Time(h) & Yield(\%) \\
\hline 1 & $\mathrm{I}$ & 3 & 96 \\
2 & $\mathrm{I}$ & 2 & 97 \\
3 & $\mathrm{Br}$ & 3 & 97 \\
4 & $\mathrm{Br}$ & 3 & 97 \\
5 & $\mathrm{Br}$ & 3 & 98 \\
7 & $\mathrm{Br}$ & 2.5 & 97 \\
\hline & $\mathrm{Br}$ & 2.5 & 96 \\
\hline
\end{tabular}

Figure 2. Schematic representation for the synthesis of COF-LZU1 and Pd/COF-LZU1 materials. (a) Proposed structures of COF-LZU1; (b) and Pd/COF-LZU1; (c,d) possessing regular microporous channels (diameter of $\sim 1.8 \mathrm{~nm}$ ), simulated with a 2D eclipsed layered-sheet arrangement. C: blue, $\mathrm{N}$ : red, and brown spheres represent the incorporated $\mathrm{Pd}(\mathrm{OAc})_{2} . \mathrm{H}$ atoms are omitted for clarity. (e) Catalytic activity test of Pd/COF-LZU1 in the Suzuki-Miyaura coupling reaction. Reprinted and adapted with permission from [118], Copyright 2011, American Chemical Society.
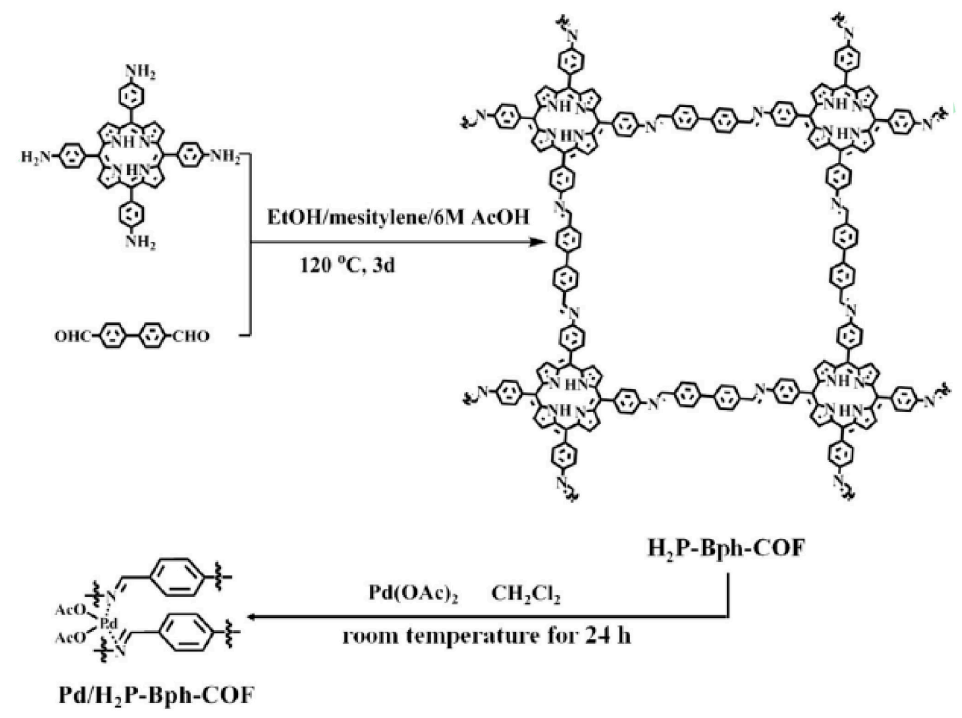

Figure 3. The preparation of $\mathrm{H}_{2} \mathrm{P}-\mathrm{Bph}-\mathrm{COF}$ and $\mathrm{Pd} / \mathrm{H}_{2} \mathrm{P}-\mathrm{Bph}-\mathrm{COF}$. Reprinted with permission from [175], Copyright 2015, Elsevier. 
Apart from imine and porphyrin COF materials, a triazine-COF could also serve as efficient amphiphilic support for $\mathrm{Pd}(0)$ nanoparticles deposition [177]. The triazine-COF was prepared by condensing 4,4',4"-(1,3,5-triazine-2,4,6-triyl)tris(oxy)tribenzaldehyde and benzene-1,4-diamine in 1,4-dioxane/mesitylene/aqueous acetic acid by heating at $120{ }^{\circ} \mathrm{C}$ for $72 \mathrm{~h}$. The as-prepared triazine COF contained both a long and flexible appendage and a nitrogen- and oxygen-rich skeleton. The nitrogen-rich moiety was responsible for the facile in-situ reduction of $\mathrm{Pd}^{2+}$ to $\mathrm{Pd}(0)$ without any external oxidants. The ether and imine units had strong interaction with $\operatorname{Pd}(0)$ nanoparticles by stabilizing and dispersing them on the COF material. This triazine-COF was very effective to catalyze the multi-fold Heck and Suzuki-Miyaura cross-couplings. The catalyst provided unprecedented high TON (turn-over number) and TOF (turn-over frequency) values for multi-fold Heck reactions compared with its homogeneous Pd, Pd-MOF and Pd/C counterparts. Extremely short reaction times $1.5 \mathrm{~h}$ and excellent isolated yield up to $99 \%$ was obtained. The recyclability test showed that after 3 cycles, the catalyst did not show apparent loss in activity. This report provided viable strategy to dock noble-metal nanoparticles into COF material without external reducing agents applying triazine monomer itself as reductant for efficient Heck and Suzuki-Miyaura cross-coupling reactions by appending long and flexible groups, forming an amphiphilic structure and incorporating more nitrogen and oxygen atoms.

Two different kinds of triazine-based imine and $\beta$-ketoenamine linked COFs TAT-DHBD and TAT-TFP could be synthesized from 1,3,5-tris-(4-aminophenyl)triazine (TAT) and 2,5-dihydroxybenzene-1,4-dicarboxaldehyde (DHBD) or 1,3,5-triformylphloroglucinol (TFP) under solvothermal conditions in dioxane/mesitylene mixture [178]. Upon $\mathrm{Pd}(\mathrm{OAc})_{2}$ inclusion into the pore space and between interlayer region of the 2D sheets, $\mathrm{Pd}(\mathrm{II})$-loaded TAT-DHBD and TAT-TFP COF materials were prepared. Sequentially, by the $\mathrm{NaBH}_{4}$ reduction of $\mathrm{Pd}(\mathrm{II})$ to $\mathrm{Pd}(0)$ nanoparticles, the $\mathrm{Pd}(0)$-loaded COFs were synthesized. Four Pd-loaded COF materials illustrated very good catalytic activity in Suzuki-Miyaura cross-coupling reaction between bromobenzene and phenylboronic acid. The best performance was obtained with Pd(0)-TAT-TFP COF catalyst which provided excellent conversion and yield for either electron-rich and electron-deficient bromobenzenes. The most appropriate substrate was 4-cyanobromobezne with phenylboronic acid which showed almost quantitative formation of 4-cyanobiphenyl only after $4 \mathrm{~h}$ by this Pd(0)-TAT-TFP COF catalyst. These four Pd-COF catalysts all displayed very good stability and reusability without apparent leaching of Pd and loss of activity.

Very recently, thioether-containing COF was reported that it could be an excellent support for ultra-fine $\mathrm{Pt}$ and $\mathrm{Pd}$ nanoparticles providing very narrow size distribution and superior stability [179]. Inspired by their own designed shape-persistent thioether-containing organic cage which hosted ultra-fine $\mathrm{Pt}$ and $\mathrm{Pd}$ nanoparticles with very narrow size-distribution, the authors elaborately designed and synthesized the PtNPs@COF and PdNPs@COF by condensing a trialdehyde and a thioether-containing diamine in a dioxane/mesitylene/aqueous acetic acid solution at $120{ }^{\circ} \mathrm{C}$ for 3 days (See Figure 4). The as-formed Thio-COF material was further complexed with $\mathrm{K}_{2} \mathrm{PtCl}_{4}$ and $\mathrm{K}_{2} \mathrm{PdCl}_{4}$ in aqueous solution, and then reduced by a methanolic $\mathrm{NaBH}_{4}$ solution to PtNPs@COF and PdNPs@COF. From a series of structural, morphological and compositional characterization, the authors demonstrated that ultra-fine $\mathrm{Pd}$ and $\mathrm{Pt}$ nanoparticles were uniformly incorporated into the pore space of the Thio-COF. The thioether functional group provided strong metal-sulfur interaction to stabilize the ultrafine noble-metal nanoparticles to prevent them from aggregation. Moreover, the long-range ordered pore-channel structure also provided assist for the stabilization of the residing external nanoparticles. The as-formed PtNPs@COF and PdNPs@COF illustrated very good catalytic activity towards 4-nitrophenol reduction and Suzuki-Miyaura cross-coupling between a variety of arylhalides and phenylboronic acid. PdNPs@COF provided excellent NMR yields up to 99\% for cross-coupling of 4-methyl-iodobenzene and phenylboronic acid to form 4-methylbiphenyl. Moreover, these two COF-based catalysts showed excellent stability and recyclability after simple centrifugation or natural settling for cycling test and almost no decrease in conversion and yield in catalytic performance after 5 th cycle tests, and no noticeable leaching of metal nanoparticles occurred. This example was 
very significant because it was the first to use thioether functional group to stabilize the narrowly distributed ultrafine noble-metal nanoparticles for effective cross-coupling reactions in a COF support.

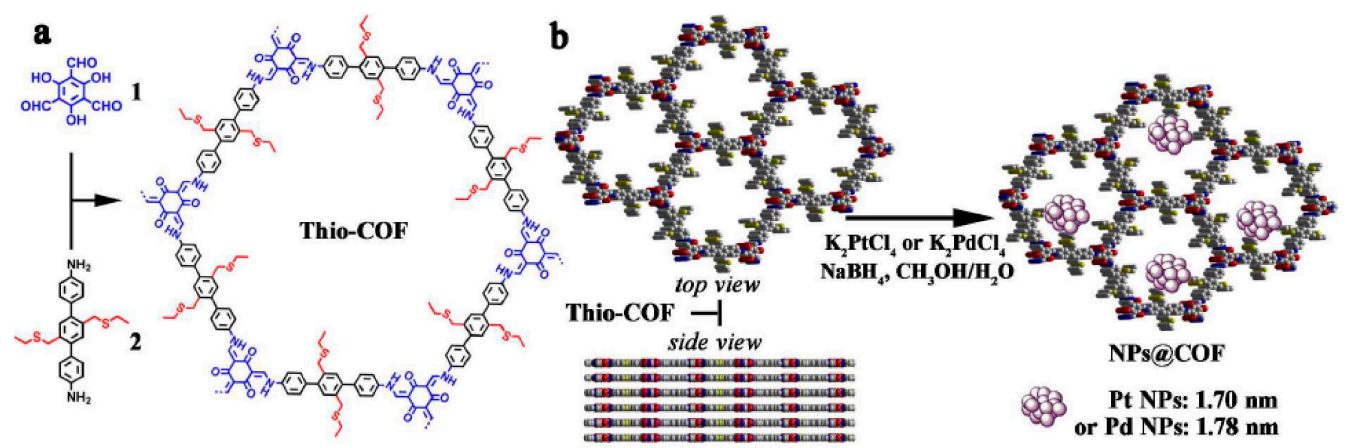

Figure 4. (a) Synthesis of Thio-COF and (b) schematic representation of the synthesis of Thio-COF supported PtNPs@COF and PdNPs@COF. Top and side views of the energy-minimized models of Thio-COF (yellow, S; blue, N; grey, C; red, O) are shown in (b). Reprinted with permission from [179], Copyright 2017, American Chemical Society.

From these successful COFs heterogeneous catalysts for Suzuki-Miyaura cross-couplings, we can deduce that suitable heteroatoms and their fine-tuned positions, COFs pore geometrical and chemical properties, and the binding modes of $\mathrm{Pd}$ transition-metal center, will all determine whether COFs catalysts can surpass their homogeneous analogues in catalytic efficiency and selectivity. Optimization and combination of robust COFs catalysts for efficient Suzuki-Miyaura reactions would still have much space for further development.

\subsection{Heck, Sonogashira and Silane-Based Cross-Coupling Reaction}

Heck cross-coupling reaction is the Pd-catalyzed coupling of aromatic or vinylic halides with unsaturated olefinic $\mathrm{C}=\mathrm{C}$ bond (See Figure 5). The catalytic cycle comprise oxidative addition of aromatic halides, coordination with olefinic $\mathrm{C}=\mathrm{C}$ bond, cis-insertion, cis- $\beta$-hydride elimination and reductive elimination. This reaction require $\mathrm{Pd}(0)$ active species. The advantages of Heck reaction is its high regio- and stereoselectivity. And the disadvantage is the costly Pd catalyst. The Sonogashira cross-coupling is the $\mathrm{Pd} / \mathrm{Cu}$ co-catalyzed coupling of terminal alkyne with aryl or vinylic halide. It comprises three basic reactions. The first step is the oxidative addition of aryl halides to $\operatorname{Pd}(0)$ center. Then a $\mathrm{Cu}$-amine complex mediates the transmetallation reaction. The last step is the reductive elimination, releasing the coupling product and regenerating the $\mathrm{Pd}(0)$ catalyst. $\mathrm{Cu}$-amine complex acts as cocatalyst to assist deprotonating the alkyne substrate.

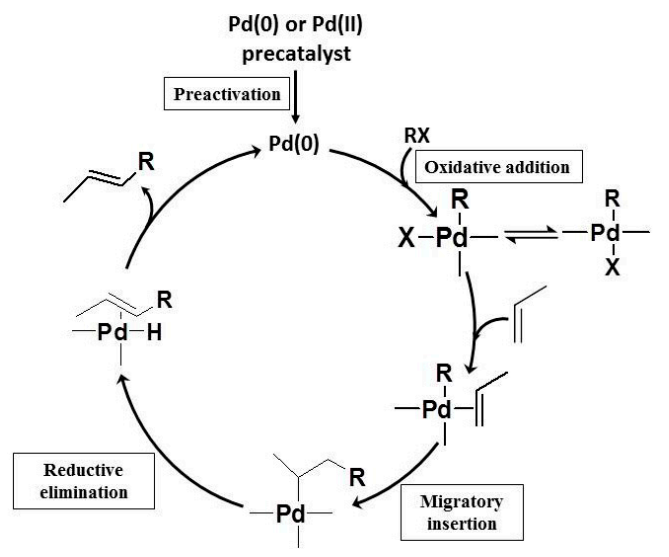

Figure 5. Scheme of Pd-catalyzed Heck reaction and its catalytic cycle. Adapted with permission from [171], Copyright 2000, ACS. 
Banerjee showed that introduction of a large number of nitrogen and oxygen atoms to the skeleton of COF material would reinforce its stability when metal nanoparticles or complexes were deposited. They showed that by the condensation of 1,3,5-triformylphloroglucinol and paraphenylenediamine in mesitylene/dioxane/aqueous acetic acid solution at $120^{\circ} \mathrm{C}$ for 3 days in inert atmosphere would generate a nitrogen- and oxygen-rich COF material (See Figure 6) [180]. The as-synthesized imine COF material was further deposited with $\mathrm{Pd}(\mathrm{II})$ complexes by immersing in a methanol solution containing $\mathrm{Pd}(\mathrm{OAc})_{2}$. The $\mathrm{Pd}(0)$ nanoparticles were generated from in-situ reduction of $\mathrm{Pd}$ (II)-COF with $\mathrm{NaBH}_{4}$. The authors demonstrated that $\mathrm{Pd}(0)$ and $\mathrm{Pd}(\mathrm{II})$ inclusion did not greatly change the crystallinity and flower-like morphology of the COF material. Moreover, the $\operatorname{Pd}(0)$-COF showed superior catalytic activity towards Heck and Sonogashira-type reaction. The Pd(II)-COF demonstrated considerably robust catalytic ability for an intramolecular $\mathrm{C}-\mathrm{H}$ activation and further $\mathrm{C}-\mathrm{C}$ coupling reaction synthesizing $9 \mathrm{H}$-carbazole from diphenylaniline. This report manifested its significance in incorporating $\mathrm{Pd}(0)$ and $\mathrm{Pd}(\mathrm{II})$ into the same COF material and applied the metal-COF composite in highly selective $\mathrm{C}-\mathrm{C}$ coupling and $\mathrm{C}-\mathrm{H}$ activation transformations. Moreover, the fact that this $\mathrm{COF}$ material demonstrated greatly enhanced stability towards aqueous, acidic and alkaline environment was very inspiring, which illustrated nitrogen and oxygen atoms would considerably increase interactions with metal nanoparticles or metal complexes.
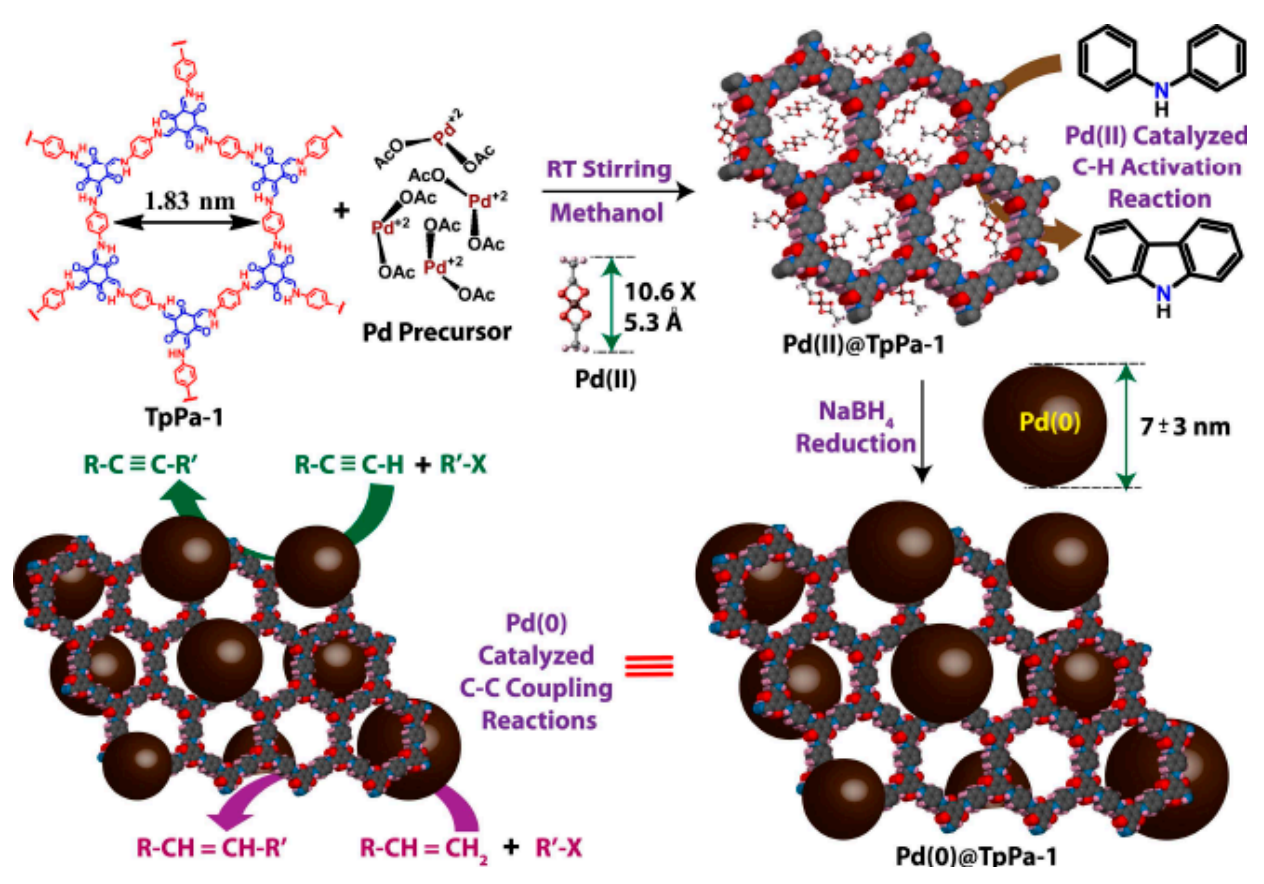

Figure 6. Synthesis of Pd(II) and Pd(0)-doped COFs (i.e., Pd(II)@TpPa-1, Pd(0)@TpPa-1) and summary of their catalytic activity towards Sonogashira, Heck and oxidative biaryl couplings. The doped $\operatorname{Pd}(0)$ nanoparticles are probably situated on TpPa- 1 surface. (The scheme is to represent the synthesis and the organization of the Pd nanoparticles on COF (TpPa-1) and it is not exactly fit to scale). Reprinted with permission [180], Copyright 2014, Royal Society of Chemistry.

Chai et al. reported that two different nitrogen ligands bipyridine and imine could be incorporated into a single COF skeleton to provide differentiated Pd coordinating sites [181]. They designed and synthesized $\mathrm{X} \%$ bpy-COF by condensing $\mathrm{X} \%$ 2,2-bipyridine-5,5'-dicarbaldehyde, $100-\mathrm{X} \%$ 4,4'-biphenyl dialdehyde and 4,4', $4^{\prime \prime}, 4^{\prime \prime \prime}$-(pyrene-1,3,6,8-tetrayl)tetraaniline (PyTTA) building blocks in a mesitylene/dioxane/3M acetic acid solution at $120^{\circ} \mathrm{C}$ for 3 days (See Figure 7). The as-formed $\mathrm{X} \%$ bpy-COF contained two different kinds of nitrogen ligands, namely, bipyridine and imine. The further $\mathrm{Pd}(\mathrm{OAc})_{2}$ complexation was furnished by a simple solution-infiltration procedure. From a variety of characterization experiments results, the authors demonstrated that $\mathrm{Pd}(\mathrm{OAc})_{2}$ coordinated with 
both bipyridine and imine unit, but in different region. $\mathrm{Pd}(\mathrm{OAc})_{2}$ combining with bipyridine mainly dwelled in the pore space, while $\mathrm{Pd}(\mathrm{OAc})_{2}$ jointing with imine resided between adjacent layer of the $2 \mathrm{D}$ COF. Furthermore, the authors demonstrated that these Pd@bpy-COF displayed very good catalytic performance towards classical Pd-catalyzed Heck reaction between a series of arylhalides and styrene. $\operatorname{Pd}(\mathrm{II}) @ 75 \%$ bpy COF showed the best catalytic ability providing $>90 \%$ yield after four consecutive runs. The superior activity for Heck reaction of these Pd@bpy-COF catalysts was attributed to the uniform dispersion and the ultra-high loading of $\mathrm{Pd}(\mathrm{OAc})_{2}$.

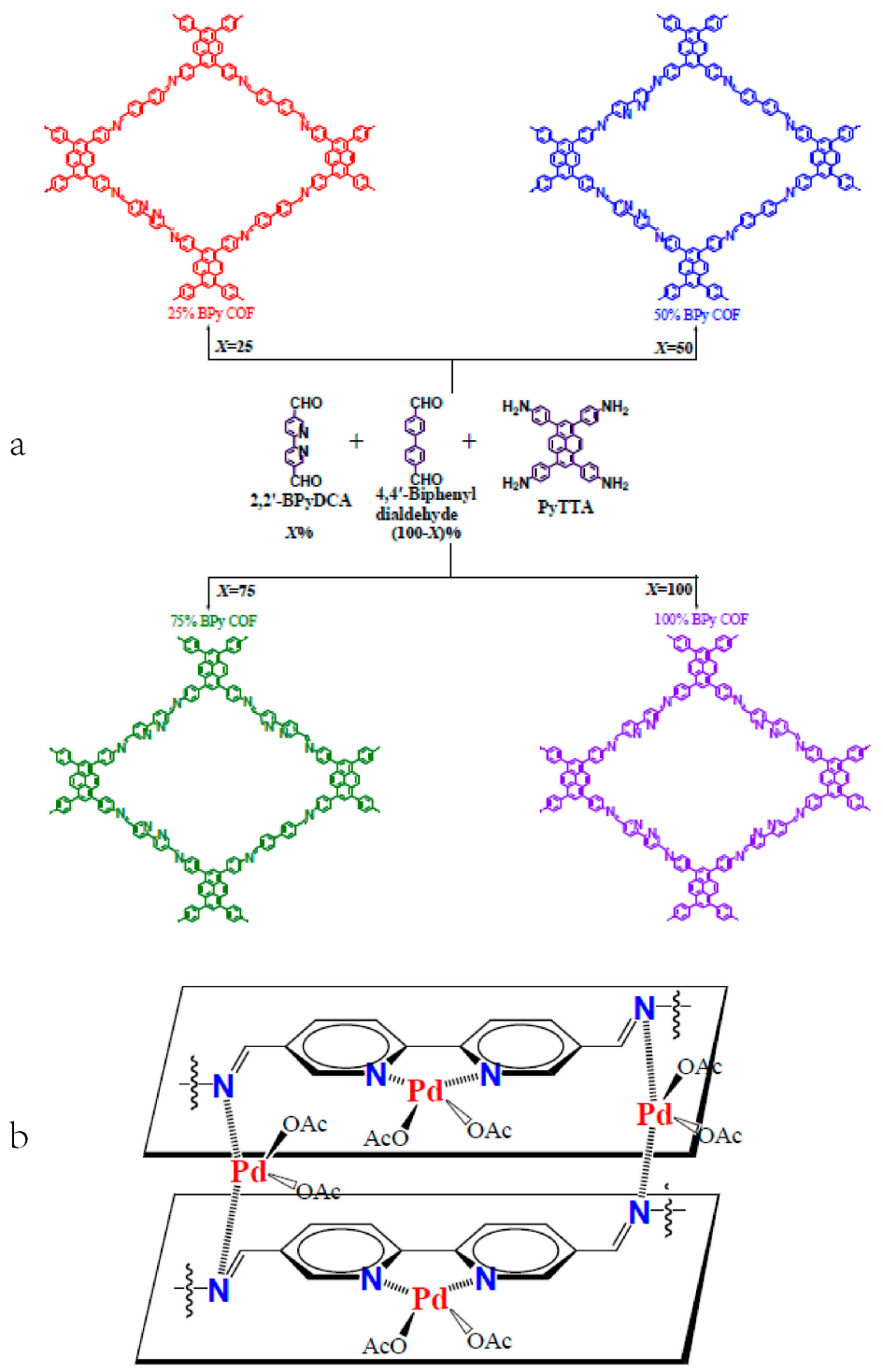

Figure 7. (a) Pore surface engineering strategy used to modulate the nitrogen content of the $2 \mathrm{D}$ imine-type COFs. (b) Scheme for the regulated $\mathrm{Pd}(\mathrm{OAc})_{2}$ coordination on bipyridine and imine groups. Reprinted with permission from [181], Copyright 2016, Elsevier.

In other occasions, $\operatorname{Pd}(0)$ nanoparticles could be generated in-situ by choosing a predesigned metal-anchored building block. Initially, a 2,2-bipyridine-5,5'-diamine palladium chloride $\left(\mathrm{bpy}-\mathrm{PdCl}_{2}\right)$ complex was formed by the coordination reaction between $\mathrm{PdCl}_{2}$ and 2,2'-bipyridine-5,5'-diamine [182]. Then, via the Schiff-base condensation between $\mathrm{Bpy}-\mathrm{PdCl}_{2}$ and 1,3,5-triformylphloroglucinol (Tp), a Pd@TpBpy COF was synthesized. This in-situ generated $\mathrm{Pd} @$ Tp-bpy COF did not require any external reducing agents for $\mathrm{Pd}(\mathrm{II})$ reduction to $\mathrm{Pd}(0)$ nanoparticles. The as-formed Pd@Tp-bpy COF showed excellent catalytic performance towards 
a tandem $\mathrm{C}-\mathrm{C}$ and $\mathrm{C}-\mathrm{O}$ bond formation reaction between 2-bromophenol and phenylacetylene. The Pd@Tp-bpy COF heterogeneous catalyst promoted tandem cyclization provided various 2-arylbenzofurans in good to excellent yields not regarding electron-rich or electron-deficient substituents on phenylacetylene or 2-bromophenol. Moreover, this keto-enamine and bipyridine anchored Pd@TpBpy COF showed very good stability and recyclability.

A triazine-based COF-SDU1-palladium hybrid could be an active catalyst for the cross-coupling between silanes and aryliodides [183]. The COF-SDU1 material was synthesized via the imine condensation reaction from tri-(4-formacylphenoxy)-1,3,5-triazine (trif) and $p$-phenylenediamine in $o$-dichlorobenzene $/ n$-butanol $/ 6 \mathrm{M} \mathrm{AcOH}$ heating at $85^{\circ} \mathrm{C}$ for 7 days (See Figure 8). The as-obtained COF solid contained two kinds nitrogen ligand azine and imine which are both suitable coordinating sites for $\mathrm{Pd}(\mathrm{II})$. After a simple solution-infiltration, mono-dispersing $\mathrm{Pd}(\mathrm{II})$ ion was docked in the 2D COF material. This Pd(II)-COF-SDU1 material showed excellent catalytic activity towards a one-pot silane oxidation-cross-coupling reaction. The transformation of phenylsilanes with aryliodides to biphenyls was effectively catalyzed in methanolic solution. A variety of electron-rich and electron-deficient aryliodides were cross-coupled with phenylsilanes in good to excellent yields. This COF material also displayed good recyclability and reusability without detectable Pd leaching and loss of activity.

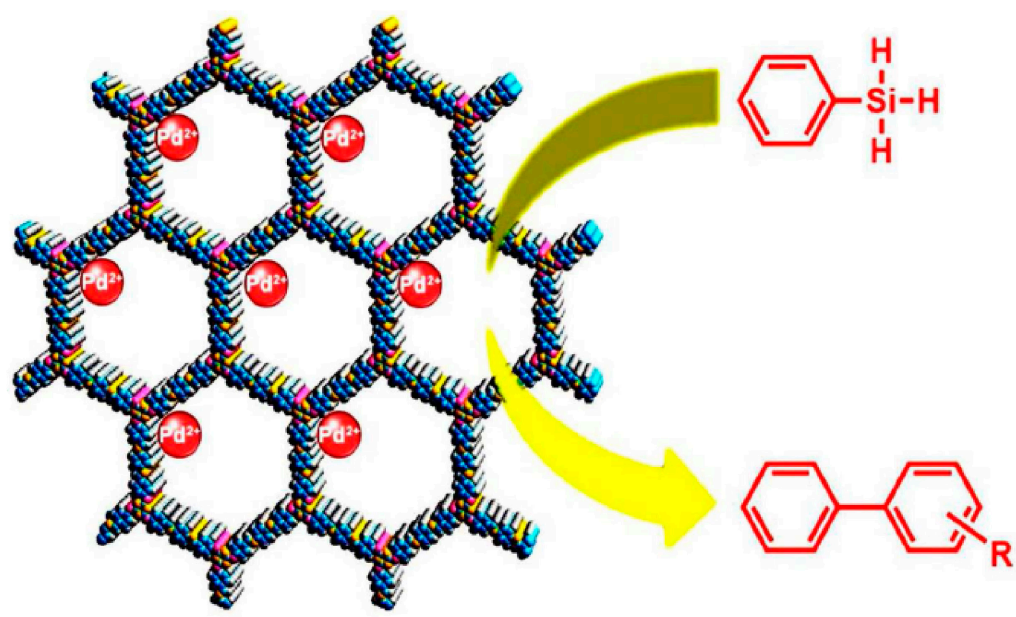

Figure 8. A triazine-based covalent organic framework-palladium hybrid for one-pot silicon-based cross-coupling of silanes and aryl iodides. C: blue, N: orange, O: purple and red spheres represent the incorporated Pd(II). H atoms are omitted for clarity. Reprinted with permission from [183], Copyright 2015, Royal Society of Chemistry.

The key points of COFs successful application in Heck, Sonogashira cross-couplings are summarized as follows: (i) very low Pd-loading (ii) very high catalytic efficiency (iii) very facile desorption of halide ions.

\subsection{Cross-Dehydrogenative-Coupling Reactions}

In 2016, a hydrazone-based COF material was reported to be used as an outstanding photocatalyst for a series of cross-dehydrogenative-coupling reaction (CDC) under visible-light illumination [184]. The hydrazone-based TFB-COF was synthesized from the Schiff-base condensation reaction of 2,5-dimethoxyterephthalohydrazide (DMTH) and 1,3,5-triformylbenzene (TFB) under solvothermal conditions (See Figure 9). The as-formed TFB-COF showed good catalytic activity towards a variety of CDC reactions between $\mathrm{N}$-phenyltetrahydroisoquinoline and nucleophilic reagents $\mathrm{CH}_{3} \mathrm{NO}_{2}$, $\mathrm{CH}_{3} \mathrm{COCH}_{3}$ and $\mathrm{PhCOCH}_{3}$ in $\mathrm{O}_{2}$ atmosphere under visible-light illumination. Good to excellent yields up to $87 \%$ were obtained by this hydrazone-based TFB-COF photocatalyst. Moreover, the conversion and selectivity did not show apparent loss after three runs of recycling test. The morphology and XRD 
peaks did not display great change. To our best knowledge, this example was the first recorded COF material without transition metal for CDC applications.

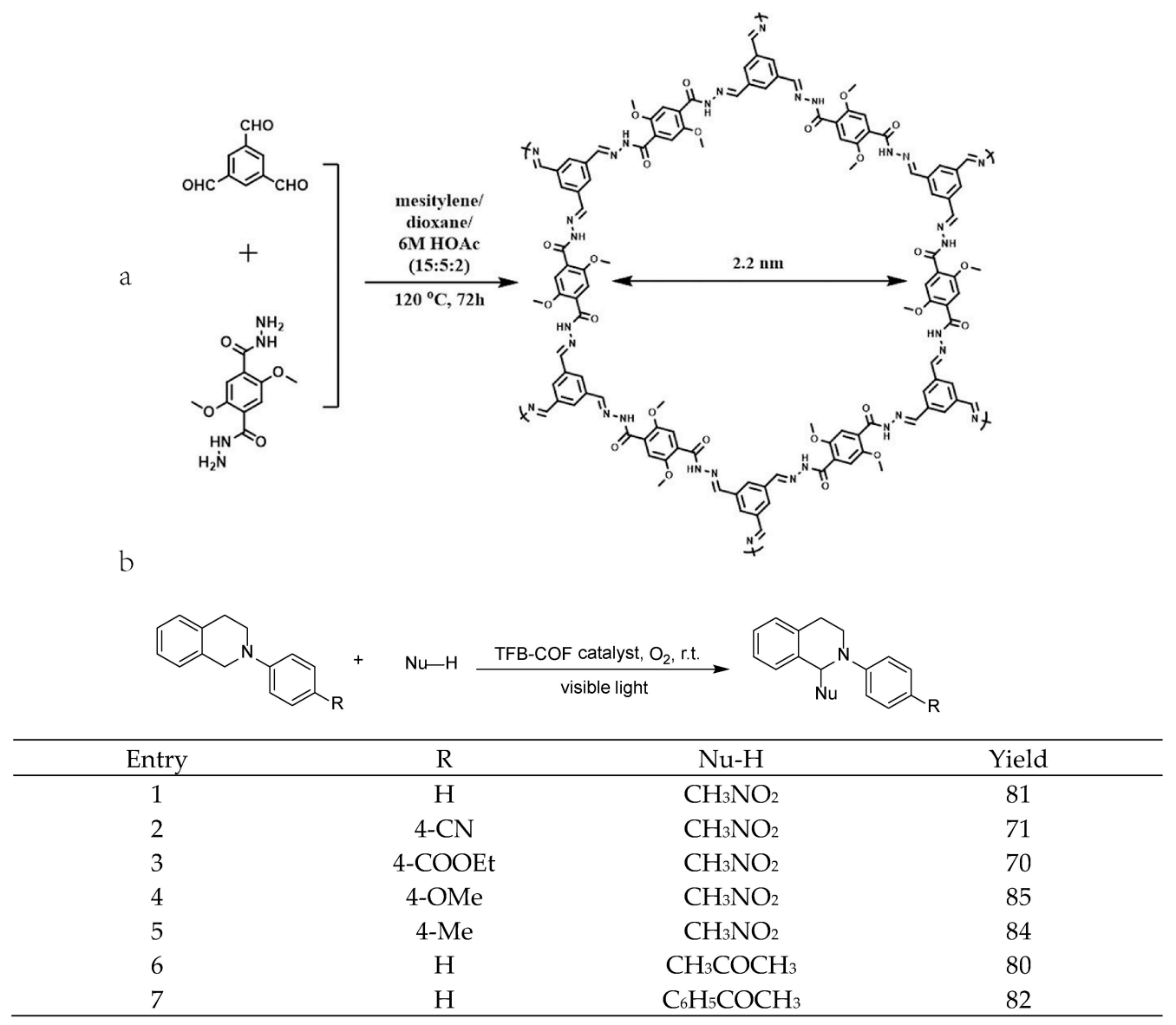

Figure 9. (a) Schematic representation for the synthesis of TFB-COF. (b) Reaction substrate extension of photocatalytic coupling reactions of $N$-aryltetrahydroisoquinolines and nucleophilic reagents using TFB-COF catalyst. Reprinted and adapted with permission from [184], Copyright 2017, Wiley.

Likewise, Liu et al. reported that another hydrazone-based 2D COF material COF-JLU5 could promote the photocatalytic oxidative transformation of $\mathrm{N}$-phenyltetrahydroisoquinoline with a variety of C-centered or P-centered nucleophiles [185]. This 2D COF-JLU5 was synthesized via the Schiff-base condensation reaction of 1,3,5-tris-(4-aminophenyl) triazine and 2,5-dimethoxyterephthaldehyde in the presence of $6 \mathrm{M}$ aqueous acetic acid using mesitylene/1,4-dioxane as the solvent at $120{ }^{\circ} \mathrm{C}$ for 3 days (See Figure 10). The as-synthesized COF-JLU5 demonstrated good crystallinity and porosity. Moreover, this hydrazone-based COF showed excellent catalytic performance towards the CDC oxidative transformation of $\mathrm{N}$-phenyltetrahydraisoquinoline with various nucleophiles. The aza-Henry, Mannich-type and C-P bond formation reactions were effectively catalyzed by this COF-JLU5 under visible-light illumination in an $\mathrm{O}_{2}$ atmosphere. Moreover, from the results of the electron-paramagnetic-resonance (EPR) characterization of singlet oxygen ${ }^{1} \mathrm{O}_{2}$ and superoxide anion in different conditions, the authors proposed a plausible mechanism for this COF photocatalytic CDC reaction. Initially, the visible-light activated COF-JLU5 abstracted an electron from $N$-phenyltetrahydroisoquinoline forming the corresponding radical cation. The radical cation was further transformed to the radical via deprotonation by superoxide anion. The further single-electron-transfer (SET) oxidation of $\mathrm{N}$-phenyltetrahydroisoquinoline radical to its cation was facilitated by superoxide anion or activated-state COF-JLU5. The finally nucleophilic attack between nitroalkane, ketones, malonates and dialkylphosphates with tetrahydroisoquinoline cation yielded the final C-C or C-P bond formation products. 
Catalysts 2018, 8, 404

13 of 35

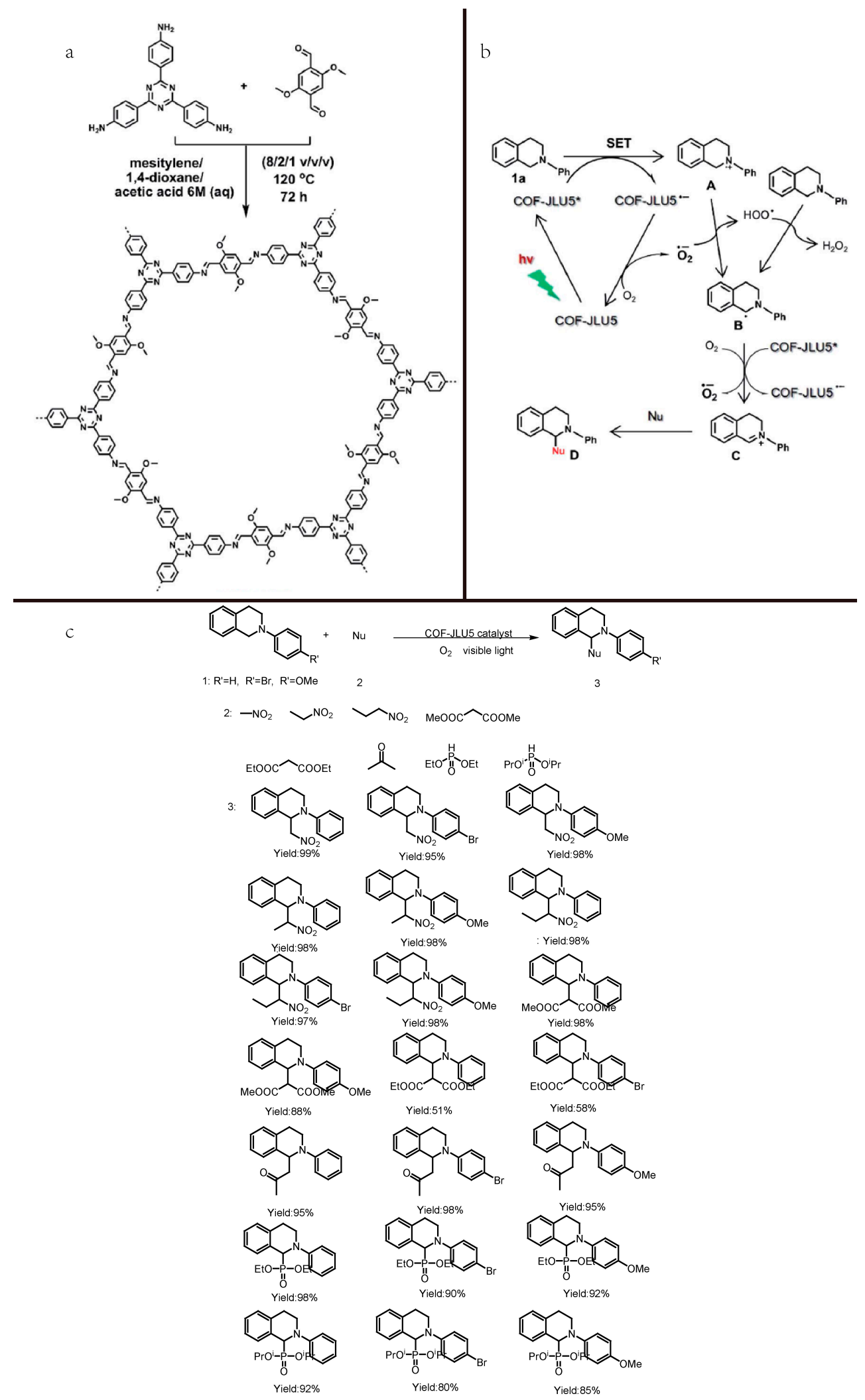

Figure 10. (a) Synthesis of COF-JLU5 by imine condensation reaction. (b) Photocatalytic C-C/C-P coupling reaction of $\mathrm{N}$-phenyltetrahydroisoquinonlines with various nucleophiles using COF-JLU5 as photocatalyst. (c) Schematics of plausible mechanism of the COF-JLU5 photocatalyzed CDC reactions. Reprinted and adapted with permission from [185], Copyright 2017, Royal Society of Chemistry. 
Despite quite rare examples yet, these COFs catalyzed cross-dehydrogenative-coupling reactions clearly show the most valuable feature of COF materials as C-C coupling catalysts, that is, without transition metal participation, their pore and channel render the formation of carbocation formation and stable enough to allow another nucleophilic reagent attacking effectively. These examples significantly differentiate homogeneous dye-sensitized singlet $\mathrm{O}_{2}$ reaction. The dye molecules cannot provide such a pore structure and catalytic platform to realize the cross-coupling reactions. The unique skeleton and independence of transition-metal catalytic center is the most attractive trait of COFs for cross-coupling reactions.

\subsection{Chiral Asymmetric C-C Bond. Formation Reaction}

In 2014, Jiang et al. described an example of a chiral-organocatalytic COF material synthesized through pore surface engineering [186]. This organocatalytic COF material was prepared by integrating a chiral pyrrolidine unit into the main-chain of porphyrin-imine COF material (See Figure 11). They first introduced ethynyl group into the imine moiety. And by the facie alkyne-azide click reaction, they grafted the triazole-substituted pyrrolidine ring to imine by a post-treatment catalyzed by $\mathrm{CuI}$ catalyst. The as-prepared COF demonstrated its activity for organocatalysis and displayed a variety of advantages in catalyzing an enantioselective asymmetric Michael-addition reaction. Although moderate diastereoselectivity (d.r.) and $e e$ values were obtained, the conversion of the reactants was much accelerated by this organocatalytic COF material (See Figure 12). And the most important was that this COF material the first time COFs materials realized enantioselectivity control in catalytic organic synthetic reaction.
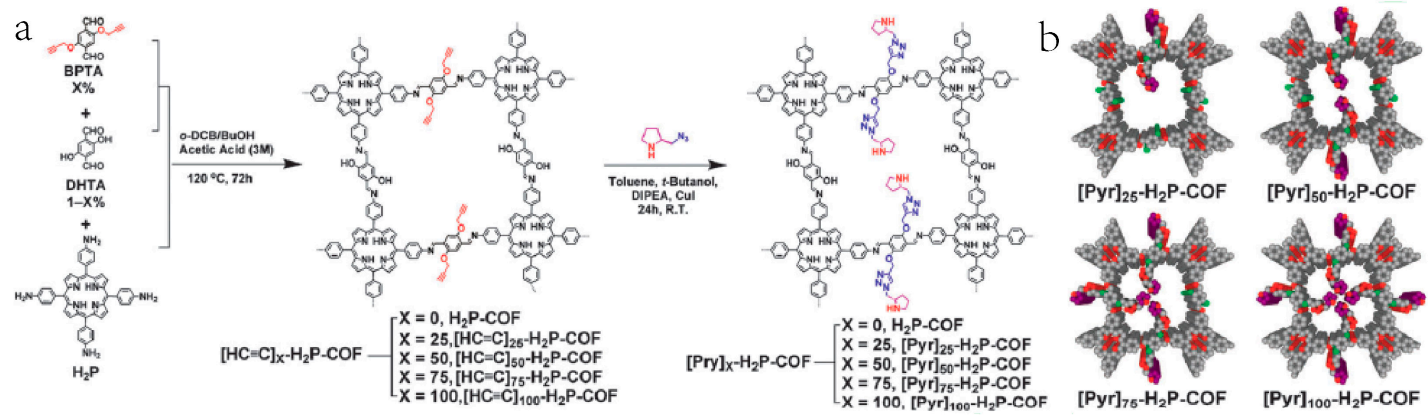

Figure 11. (a) The general strategy for the pore surface engineering of imine-linked COFs via a condensation reaction and click chemistries (the case for $X=50$ was exemplified). (b) A graphical representation of $[\mathrm{Pyr}]_{X}-\mathrm{H}_{2} \mathrm{P}-\mathrm{COF}$ with different densities of catalytic sites on the pore walls (gray: carbon, red: nitrogen, green: oxygen, purple: carbon atoms of the pyrrolidine unit; hydrogen is omitted for clarity). Reprinted with permission from [186], Copyright 2014, Royal Society of Chemistry.

\begin{tabular}{|c|c|c|c|}
\hline & $\begin{array}{l}\text { Time for } 100 \% \\
\text { conversion }(\mathrm{h})\end{array}$ & $\mathrm{dr}$ & ee $(\%)$ \\
\hline Control & 3.3 & $60 / 40$ & 49 \\
\hline$[\mathrm{Pyr}]_{25}-\mathrm{H}_{2} \mathrm{P}-\mathrm{COF}$ & 1 & $70 / 30$ & 49 \\
\hline$[\mathrm{Pyr}]_{50}-\mathrm{H}_{2} \mathrm{P}-\mathrm{COF}$ & 2.5 & $70 / 30$ & 50 \\
\hline$[\mathrm{Pyr}]_{75}-\mathrm{H}_{2} \mathrm{P}-\mathrm{COF}$ & 5 & $70 / 30$ & 51 \\
\hline$[\mathrm{Pyr}]_{100}-\mathrm{H}_{2} \mathrm{P}-\mathrm{COF}$ & 9 & $65 / 35$ & 44 \\
\hline Amorphous polymer 1 & 43 & $70 / 30$ & 48 \\
\hline Amorphous polymer 2 & 65 & $65 / 35$ & 46 \\
\hline
\end{tabular}

Figure 12. Comparison of the pyrrolidine control, amorphous nonporous polymers, and COFs as catalysts for a Michael addition reaction. Reprinted with permission from [186], Copyright 2014, Royal Society of Chemistry. 
In 2015, Jiang et al. reported the design and synthesis of another organocatalytic COF material on Nature Chemistry [187]. This was the milestone event for COF materials applied for organic synthetic purpose. The authors discovered that introduction of methoxy group in edge unit would greatly increase the stability of COF material against humidity, acidity and basicity since the methoxy group reinforced the interlayer interaction. The COF material was synthesized by condensing triphenylbenzenetriamine (TPB), 2,5-bis(2-propynyloxy)terephthalaldehyde (BPTA) and 2,5-dimethoxyterephthalaldehyde (DMTA) (See Figure 13). The alkynyl-containing $[\mathrm{HC} \equiv \mathrm{C}]_{x}$-TPB-DMTA-COFs were further transformed to $[(S)-\mathrm{Py}]_{\mathrm{x}}-\mathrm{TPB}-\mathrm{DMTP}-\mathrm{COFs}$ by a post-synthetic click reaction with (S)-2-(azidomethyl)pyrrolidine catalyzed by CuI catalyst. The as-formed [(S)-Py $]_{x}$-TPB-DMTA-COFs demonstrated extremely strong stability against boiling water, $12 \mathrm{M} \mathrm{HCl}$ and $14 \mathrm{M} \mathrm{NaOH}$ solution soaking. The COF material displayed very little reduction in crystallinity and porosity after these harsh condition treatments. The XRD diffraction peaks intensities show no apparent decrease and the Brunauer-Emmett-Teller (BET) and Langmuir surface area almost remained unchanged. Besides extraordinary stability and uncompromised crystallinity and porosity, the most significant point of this COF material was its functionality to catalyze chiral asymmetric organic reactions. For a typical organocatalytic asymmetric Michael-addition between unactivated cyclohexanones and nitrostyrenes, this $\mathrm{COF}$ material displayed superior catalytic activity compared with its homogeneous counterpart. The COF material required only half the time to complete the transformation with similar excellent $e e$ and d.r. values in contrast with the homogeneous organocatalyst. After 5-cycle reusability test, this COF material did not show any apparent loss in catalytic activity. The shining point of this COF material was its combination of unprecedented stability, good crystallinity, and highly developed mesoporous structure with very powerful catalytic ability, accelerated reaction kinetics, excellent yields, d.r. and ee value for chiral asymmetric Michael addition in aqueous solution (See Figure 13d.)

Apart from above-mentioned chiral organocatalyst incorporated COF materials for asymmetric organic transformations and noble-metal incorporated COF materials for achiral organic transformations, homochiral organocatalytic COF skeleton could also be a perfect support for $\mathrm{Pd}$ nanoparticle to catalyze asymmetric reductive Heck reaction which was conventionally catalyzed by organometallic Pd species with chiral ligands [188]. The Pd nanoparticle dispersed in a chiral COF (CCOF) skeleton could effectively be a heterogeneous catalyst for asymmetric Henry and reductive Heck reaction providing excellent isolated yields and $e e$ values. The CCOF was synthesized by a condensing reaction between cyanuric chloride and $S$-(+)-2-methylpiperazine with $\mathrm{K}_{2} \mathrm{CO}_{3}$ in a dioxane solution, Furthermore, $\operatorname{Pd}(0)$ nanoparticles were included into the CCOF material by in-situ reduction of $\mathrm{Pd}\left(\mathrm{NO}_{3}\right)_{2}$ methanolic solution with $\mathrm{NaBH}_{4}$ in $\mathrm{CCOF}$ aqueous suspending solution (see Figure 14). The as-formed Pd@CCOF was uniformly dispersed between CCOF 2D layer, not residing in the pore space due to PdNPs large size $(2-5 \mathrm{~nm})$ compared with the CCOF micropore $(1.5 \mathrm{~nm})$. The incorporation of $\mathrm{Pd}$ nanoparticles greatly influenced the porous structure of CCOF, enlarging its BET surface area and pore size in certain amount. Furthermore, the authors demonstrated the synergistic catalytic activity by subjecting the Pd@CCOF catalyst in typical Henry and reductive Heck reaction conditions. To the authors delight, the Pd@CCOF catalyst displayed extremely superior catalytic ability towards these two reactions providing excellent yield up to $99 \%$ and perfect $e e$ value up to $97 \%$. To our best knowledge, this was the first example of a heterogeneous Pd-catalyzed chiral asymmetric reductive Heck reaction. The Pd@CCOF material illustrated satisfactory recyclability and reusability after 5 cycles reuse almost without apparent loss of catalytic activity providing isolated yield up to $93 \%$ and $e e$ value $91 \%$ for the 5th cycle test. This report of Pd@CCOF material manifested its importance due to that it was the first COF material combining noble-metal catalyst with chiral organocatalyst in a single COF carrier to fulfill asymmetric transformations previously catalyzed by homogeneous organometallic compounds with complex and elaborately designed chiral ligands. 


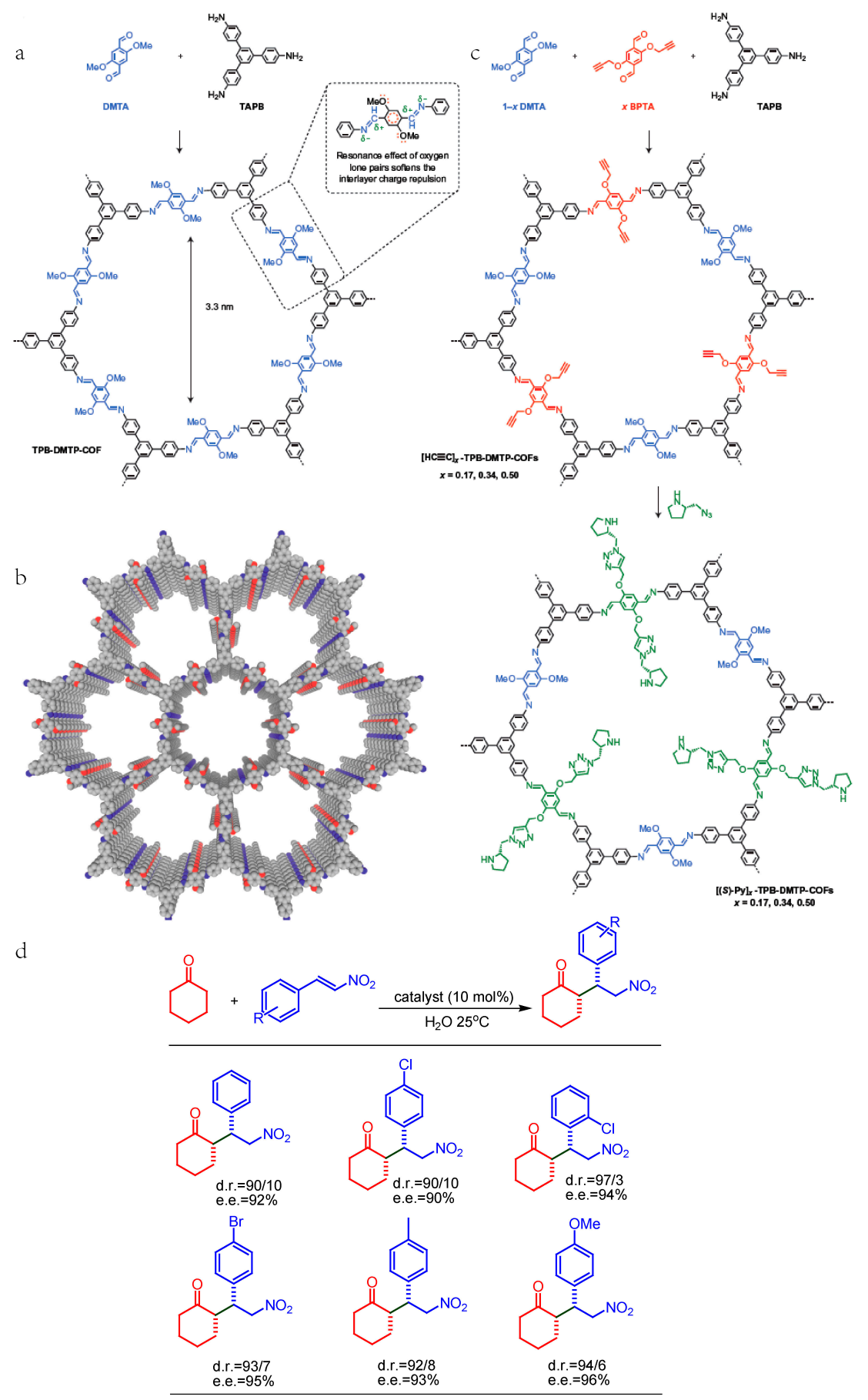

Figure 13. Synthesis and structure of stable crystalline porous COFs. (a) Synthesis of TPB-DMTP-COF through the condensation of 2,5-dimethoxyterephthalaldehyde (DMTA, blue) and TPB (black). Inset: The structure of the edge units of TPB-DMTP-COF and the resonance effect of the oxygen lone pairs that weaken the polarization of the $\mathrm{C}=\mathrm{N}$ bonds and soften the interlayer repulsion in the COF. (b) Graphic view of TPB-DMTP-COF (red, O; blue, N; grey, C; hydrogen is omitted for clarity). (c) Synthesis of chiral COFs ([(S)-Py $]_{x}-$ TPB-DMTP-COFs, $x=0.17,0.34$ and 0.50; blue, DMTA; black, TAPB; red, BPTA; green, (S)-Py sites) via channel-wall engineering using a three-component condensation followed by a click reaction. (d) Scope of reactants. Different $\beta$-nitrostyrene derivatives investigated for the Michael reactions catalyzed with chiral COFs, their products, e.e. yields and d.r. values (red, cyclohexanone; green, newly formed $\mathrm{C}-\mathrm{C}$ bond; blue, nitrostyrene derivatives). $\mathrm{R}$, substituent $\mathrm{H}, \mathrm{Cl}, \mathrm{Br}$, Me or OMe. Reprinted with permission from Reference [187], Copyright 2015, Springer. 


\begin{tabular}{ccccc} 
a & & & & \\
\hline Entry & Ar-CHO & yield & ee & config \\
\hline 1 & Ph-CHO & 97 & 95 & $\mathrm{R}$ \\
2 & $4-(\mathrm{Me})-\mathrm{Ph}-\mathrm{CHO}$ & 88 & 81 & $\mathrm{R}$ \\
3 & $3-(\mathrm{Me})-\mathrm{Ph}-\mathrm{CHO}$ & 87 & 82 & $\mathrm{R}$ \\
4 & $4-(\mathrm{MeO})-\mathrm{Ph}-\mathrm{CHO}$ & 82 & 81 & $\mathrm{R}$ \\
5 & 3-(MeO)-Ph-CHO & 80 & 79 & $\mathrm{R}$ \\
6 & $4-\left(\mathrm{NO}_{2}\right)-\mathrm{Ph}-\mathrm{CHO}$ & 99 & 97 & $\mathrm{R}$ \\
7 & 3-NO2-Ph-CHO & 94 & 88 & $\mathrm{R}$ \\
8 & $4-(\mathrm{F})-\mathrm{Ph}-\mathrm{CHO}$ & 96 & 95 & $\mathrm{R}$ \\
9 & $4-(\mathrm{Br})-\mathrm{Ph}-\mathrm{CHO}$ & 92 & 93 & $\mathrm{R}$ \\
10 & 2-(Br)-Ph-CHO & 90 & 90 & $\mathrm{R}$ \\
11 & $4-(\mathrm{Cl})-\mathrm{Ph}-\mathrm{CHO}$ & 94 & 95 & $\mathrm{R}$ \\
12 & $4-(\mathrm{CN})-\mathrm{Ph}-\mathrm{CHO}$ & 99 & 97 & $\mathrm{R}$ \\
13 & $4-(\mathrm{OH})-\mathrm{Ph}-\mathrm{CHO}$ & 96 & 90 & $\mathrm{R}$ \\
14 & Biphenyl-CHO & 5 & $\mathrm{ND}$ & $\mathrm{ND}$ \\
15 & Anthracene-CHO & ND & ND & ND \\
\hline
\end{tabular}

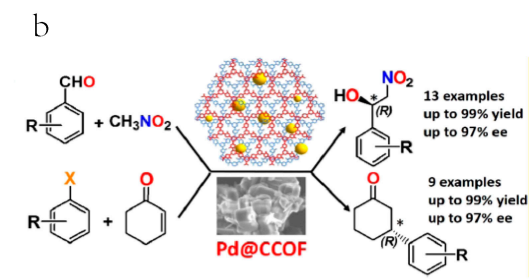

Figure 14. (a) Scope of different $\beta$-nitrostyrene derivatives with cyclohexanone investigated for the Michael-addition reactions catalyzed with Pd@CCOF (b) Pd NPs-Loaded homochiral COF for heterogeneous asymmetric catalysis. Reprinted and adapted with permission from [188], Copyright 2017, American Chemical Society.

Recently Cui et al. adopted a multivariate strategy to design and synthesize a family of two-component and three-component 2D CCOF for the purpose of asymmetric catalytic organic synthesis [189]. Three binary and four tertiary 2D CCOFs were prepared via the imine condensation reaction between 2,5-dimethoxy-1,4-terephthalaldehyde (DMTA), 1,3,5-tris(4-aminophenyl) benzene (TPB1) and four L-proline- and L-imidazolidine-based TPB derivatives. The crystalline CCOFs were prepared via two-step condensation and deprotection procedure (see Figure 15). The as-prepared CCOFs demonstrated very high catalytic activity towards three kinds of meaningful asymmetric organic transformations, namely, $\alpha$-aminooxylation, aldol and Diels-Alder reactions. The CCOF materials provided excellent yields, diastereoselectivity and enantioselectivity. The catalytic performance of the CCOF surpassed the homogeneous chiral proline and imidazolidinone catalyst and other heterogeneous support catalyst such as imidazolidinone-grafted mesoporous silica and proline-MOFs in both diastereoselectivity and enantioselectivity. This report manifested its importance in that it built a toolbox of CCOFs for asymmetric organic transformations by a multivariate strategy.

Cui et al. reported two imine-based chiral TADDOL (2,2-dimethyl- $\alpha, \alpha, \alpha_{1}, \alpha_{1}$-tetraaryl-1,3-dioxolane $-4,5$-dimethanol) COF materials CCOF-1 and CCOF-2, which could catalyze the asymmetric addition reaction between $\mathrm{Et}_{2} \mathrm{Zn}$ and a variety of aromatic aldehyde providing excellent conversions and ee values [190]. These two CCOFs were synthesized via the imine condensation reaction between tetraaryl-1,3-dioxolane-4,5-dimethanols (TADDOLs) derivatives TTA and TTPA with 4,4'-diaminodiphenylmethane (4,4'-DADPM) (Figure 16). The as-formed TADDOL CCOF-1 and CCOF-2 acted as excellent heterogeneous catalysts for the asymmetric addition reaction between $\mathrm{Et}_{2} \mathrm{Zn}$ and aromatic aldehydes after treatment with $\mathrm{Ti}(\mathrm{OiPr})_{4}$. Up to $99 \%$ conversion and $>90 \%$ ee value was realized when the heterogeneous catalytic reaction was conducted at $-30{ }^{\circ} \mathrm{C}$. The $\mathrm{CCOF}-1 / \mathrm{CCOF}-2$ chiral catalyst also displayed very good recyclability and reusability after consecutive four runs providing comparable conversion and $e e$ value with the fresh one. This example was a milestone discovery in COF application to catalysis due to that it was among the first main-chain chiral COFs to fulfill asymmetric organic transformations. 


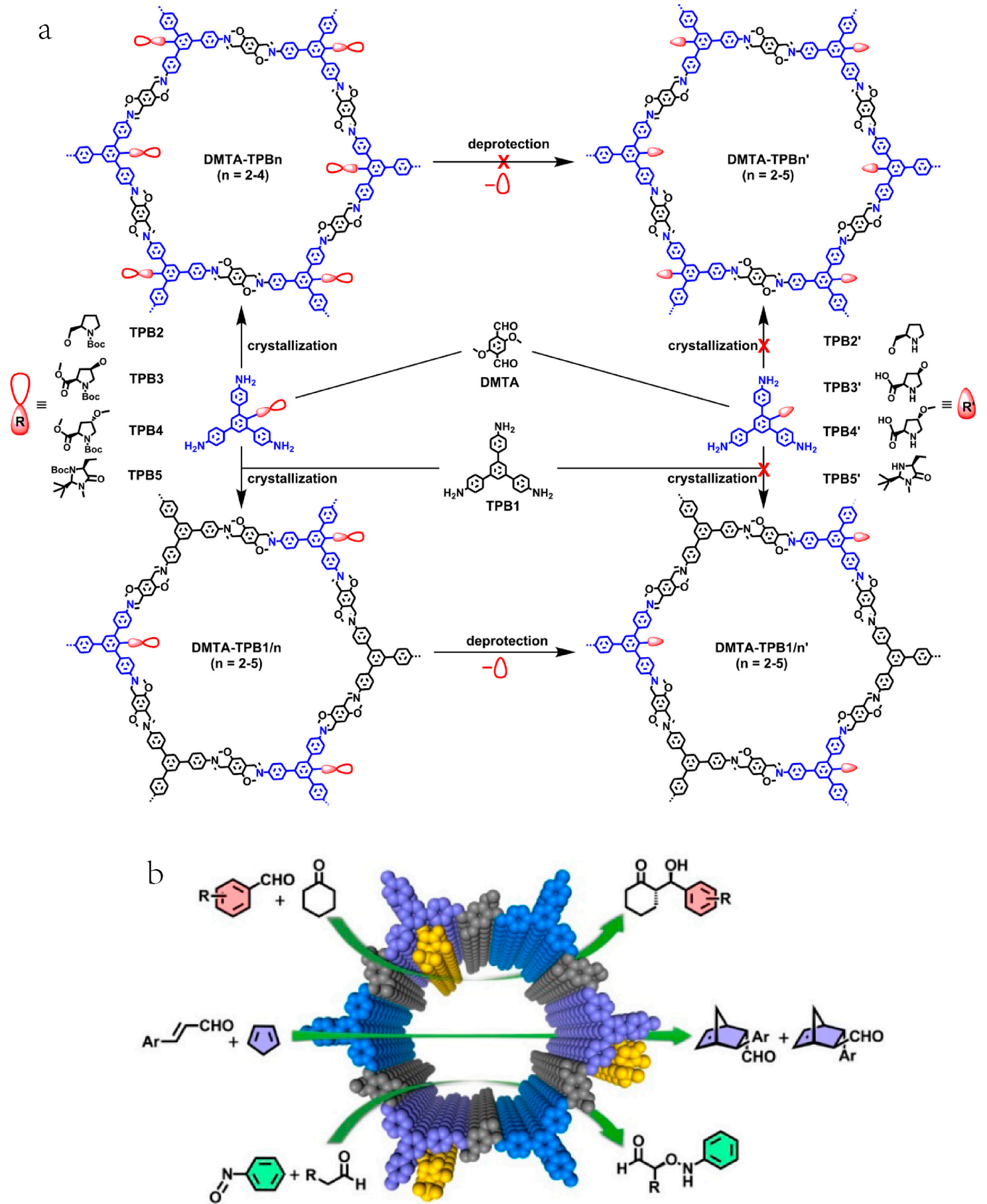

Figure 15. (a) Synthesis of the CCOFs. Blue and red color represents TPB units, and black color represents DMTA units (b) Multivariate chiral COFs with controlled crystallinity and stability for asymmetric catalysis. Blue represents TPB units, grey represents imine units and yellow represents $\mathrm{R}$ and $\mathrm{R}^{\prime}$ units in subfigure a. Reprinted with permission from [189], Copyright 2017, American Chemical Society. 


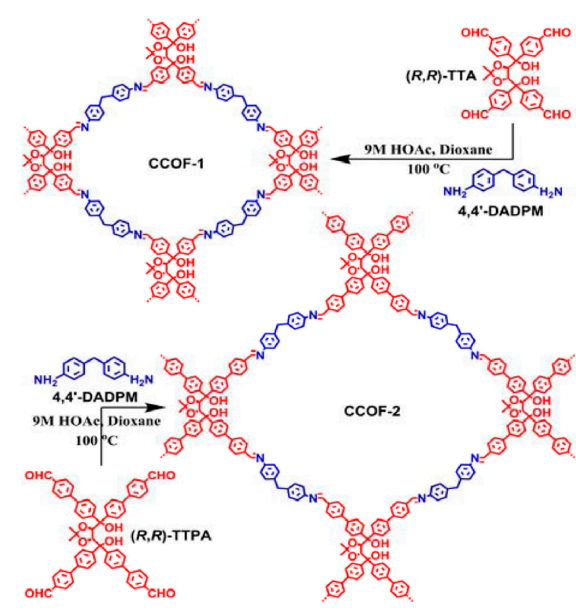

b

\begin{tabular}{|c|c|c|c|c|}
\hline Entry & CCOF & $\mathrm{Ar}$ & Conv( $(\%)$ & ee( $(\%)$ \\
\hline 1 & 1 & $\mathrm{C}_{6} \mathrm{H}_{5}$ & 99 & 90 \\
\hline 2 & 2 & $\mathrm{C}_{6} \mathrm{H}_{5}$ & 99 & 85 \\
\hline 3 & 1 & $p-\mathrm{MeC}_{6} \mathrm{H}_{4}$ & 99 & 93 \\
\hline 4 & 2 & $p-\mathrm{MeC}_{6} \mathrm{H}_{4}$ & 99 & 88 \\
\hline 5 & 1 & $p-\mathrm{ClC}_{6} \mathrm{H}_{4}$ & 94 & 90 \\
\hline 6 & 2 & $p-\mathrm{ClC}_{6} \mathrm{H}_{4}$ & 96 & 86 \\
\hline 7 & 1 & $\mathrm{C}_{6} \mathrm{H}_{5} \mathrm{C}=\mathrm{CH}$ & 99 & 91 \\
\hline 8 & 2 & $\mathrm{C}_{6} \mathrm{H}_{5} \mathrm{C}=\mathrm{CH}$ & 99 & 85 \\
\hline 9 & 1 & 2-naphthyl & 96 & 94 \\
\hline 10 & 2 & 2-naphthyl & 96 & 95 \\
\hline 11 & 1 & 1-pyrenyl & 97 & 82 \\
\hline 12 & 2 & 1-pyrenyl & 96 & 74 \\
\hline 13 & 1 & coronenyl & $<5$ & ND \\
\hline 14 & 2 & coronenyl & $<5$ & ND \\
\hline
\end{tabular}

Figure 16. (a) Synthesis of the CCOFs. (b) Addition of diethylzinc to aromatic aldehydes catalyzed by CCOF/Ti. Reprinted and adapted with permission from [190], Copyright 2016, American Chemical Society.

Cui et al. reported that two $\mathrm{Zn}$ (salen)-based 2D CCOFs were synthesized by condensation of chiral 1,2-diaminocyclohexane and trisalicylaldehyde or tributyltrisalicylaldehyde (Figure 17) [191].

a
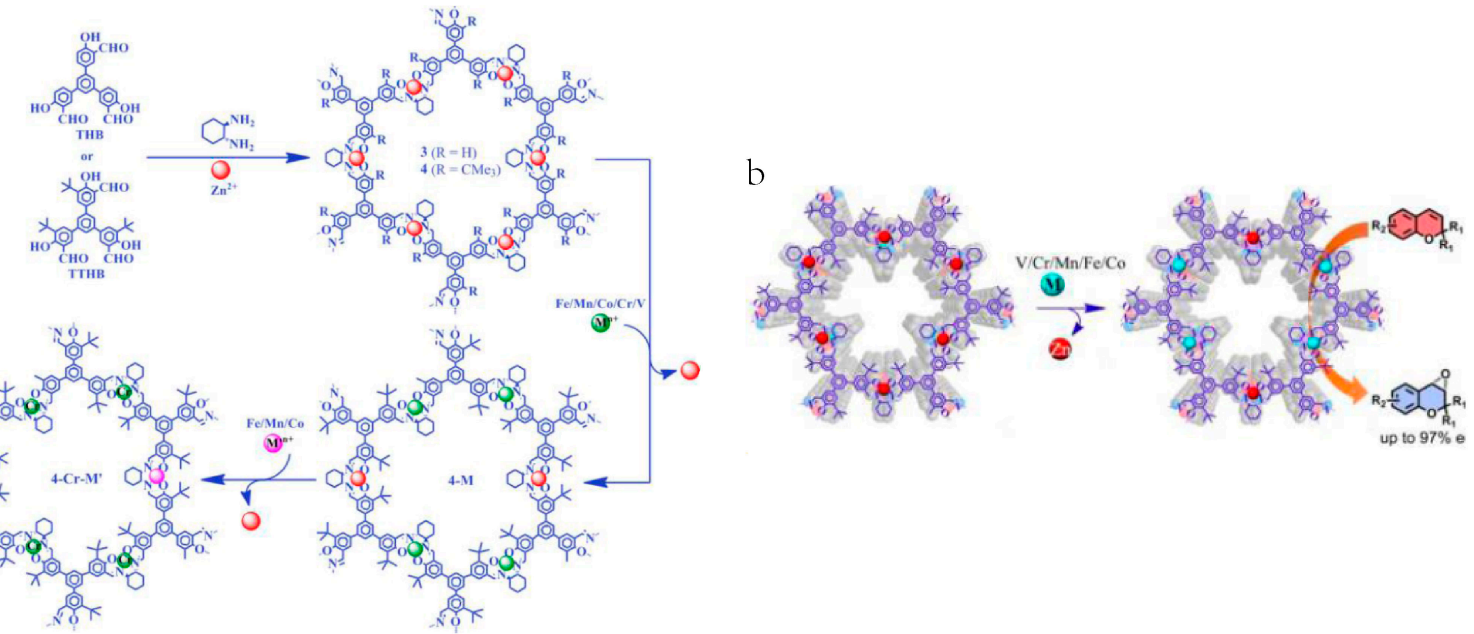

Figure 17. (a) Synthesis of the CCOF. (b) Chiral COFs with high chemical stability for heterogeneous asymmetric catalysis. Reprinted with permission from [191], Copyright 2017, American Chemical Society.

They found that the bulky tributyltrisalicylaldehyde containing CCOF possessed superior stability. And these two CCOFs were further complexed with a variety of metal ion such as $\mathrm{Zn}$, $\mathrm{Fe}, \mathrm{Mn}, \mathrm{Cr}, \mathrm{V}$ and $\mathrm{Co}$. The M(salen)-based CCOFs demonstrated very good catalytic activity to a variety of chiral asymmetric organic synthetic reactions, such as V-salen CCOF catalyzed cyanation reaction of aldehydes, Diels-Alder cycloaddition reaction catalyzed by Co-salen CCOF, epoxidation catalyzed by Fe-salen $\mathrm{CCOF}$ and Mn-salen CCOF, aminolysis opening of epoxides catalyzed by $\mathrm{Cr}$-salen $\mathrm{CCOF}$ and the tandem one-pot epoxidation and aminolysis opening of alkene catalyzed by a bimetallic $\mathrm{Cr}$ (salen)-Mn(salen)-CCOF heterogeneous catalyst. These $\mathrm{M}$ (salen)-CCOF catalyzed reactions not only provided satisfactory yields, but also realized excellent controls of enantioselectivity and diastereoselectivity. Moreover, the good recyclability and reusability was proved in the case of 
V-salen CCOF catalyzed cyanation of aldehydes, which showed almost no loss of enantioselectivity, and conversion after 5 runs of cycle tests.

Two chiral COFs LZU-72 and LZU-76 acted as efficient heterogeneous organocatalyst and effectively catalyzed the asymmetric aldol reaction providing excellent yield and enantioselectivity [192]. The chiral COFs were synthesized by the bottom-up approach from condensing the chiral block units other than a post-synthesis procedure. The authors discovered that the linear-structured 4,4'-diamino- $p$-terphenyl could act as the modifying sites for chiral blocks due to its structural rigidity. The chiral building block (S)-4,4'-(2-(pyrrolidin-2-yl)-1H-benzimidazole-4,7-diyl)dianiline was incorporated into the achiral skeleton. The further condensation reaction between 1,3,5-triformylbenzene and 1,3,5-triformylphloroglucinol with the chiral diamine formed the final chiral COFs LZU-72 and LZU-76 (see Figure 18). These two organocatalytic COFs showed outstanding catalytic performance towards a value-added C-C bond forming reaction, asymmetric aldol reaction. LZU-76 displayed the best performance providing 94.0: 6.0 e.r. value, which was comparable with the benchmark homogeneous analogue (S)-4,7-diphenyl-2-(pyrrolidin-2-yl)-1H-benzimidazole (DPBIP) catalyst for the asymmetric aldol reaction. The authors proposed that the direct construction of chiral COFs from chiral building blocks provided a promising pathway to design and synthesize novel chiral COF structures which could accommodate a large amount of uniform chiral catalyst moiety for more meaningful value-added organic transformations.

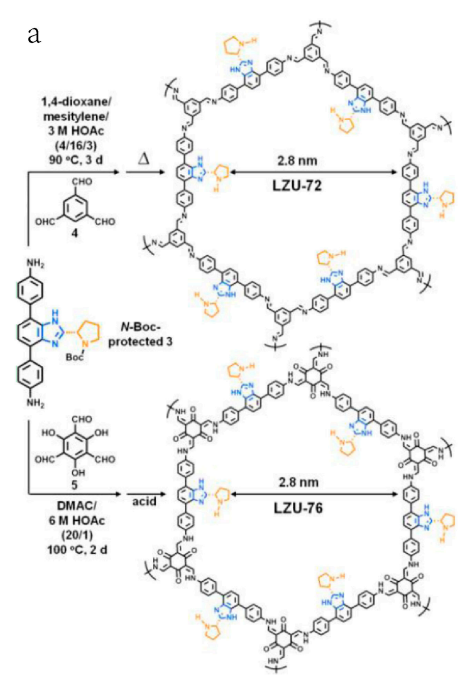

b

\begin{tabular}{|c|c|c|c|c|c|}
\hline \multirow{2}{*}{$\begin{array}{l}\mathrm{Ar}-\mathrm{CH} \\
\text { Entry } \\
\end{array}$} & \multicolumn{5}{|c|}{$\begin{array}{c}\text { catalyst }(30 \mathrm{~mol} \%) \\
\text { TFA } \\
\text { acetone, } 30^{\circ} \mathrm{C}\end{array}$} \\
\hline & $\mathrm{Ar}$ & Catalyst & Time(h) & Yield(\%) & e.r. \\
\hline 1 & $4-\mathrm{NO}_{2} \mathrm{Ph}$ & LZU-76 & 18 & 73 & $94.0: 6.0$ \\
\hline 2 & $2-\mathrm{NO}_{2} \mathrm{Ph}$ & LZU-76 & 18 & 84 & $93.7: 6.3$ \\
\hline 3 & 4-CNPh & LZU-76 & 48 & 71 & 93.5:6.5 \\
\hline 4 & 4-BrPh & LZU-76 & 96 & 46 & 88.4:11.6 \\
\hline 5 & 2-naphthyl & LZU-76 & 80 & 25 & 91.4:8.6 \\
\hline 6 & $4-\mathrm{NO}_{2} \mathrm{Ph}$ & DPBIP & 6 & 82 & 993.1:6.9 \\
\hline
\end{tabular}

Figure 18. (a) Schematic representation for the direct construction of chiral COFs, LZU-72 and LZU-76. (b) Catalytic activity test of LZU-76 in asymmetric aldol reaction. Reprinted and adapted with permission from [192], Copyright 2016, American Chemical Society.

From the above-mentioned examples, it is feasible to incorporate chiral units or moieties into $\mathrm{COFs}$ structure for asymmetric enantioselective catalysis. COFs pore and tunnel structure would be further self-assembled into helical structure to fulfill more challenging chiral synthesis.

\subsection{Bimetallic or Bifunctional COF-Catalyzed C-C Bonds Formations}

The first bifunctional organocatalytic COF material was designed and realized by Banerjee et al., which was stable in aqueous and acidic condition [193]. This COF material was prepared via the Schiff-base condensation between 2,3-dihydroxyterephthalaldehyde (2,3-Dha) and 5,10,15,20-tetrakis (4-aminophenyl)-21H,23H-porphine unit (Tph) in dichlorobenzene $(o-\mathrm{DCB}$,$) and dimethylacetamide$ (DMAc) with a catalytic amount of $6.0 \mathrm{M}$ acetic acid. The as-synthesized COF material displayed unprecedented stability in water and acidic solution due to the catechol group, the presence of trans conformation of imine bonds and intramolecular hydrogen bonding $[-\mathrm{OH} \cdot \mathrm{N}=\mathrm{C} ; \mathrm{D}=2.579, \mathrm{~d}=1.858 \AA$, 
and $y=146.11]$, which have been confirmed from the monomer crystal structure (see Figure 19). Moreover, since the COF material was consisted from the Dha unit which contains weak acidic catechol groups and Tph group containing basic pyrrole groups and imine $\mathrm{C}=\mathrm{N}$ bonds, this $\mathrm{COF}$ possessed acidic and basic sites providing it as a promising bifunctional heterogeneous catalyst. In a model cascade deacetalization-Knoevenagel reaction, this COF material demonstrated excellent isolated yield up to $96 \%$. The deacetalization of benzaldehydedimethylacetal was catalyzed by the acidic sites of this COF catalyst, while the further Knoevenagel reaction between benzaldehyde and malonitrile was effectively accelerated by the basic sites of the Dha-Tph-COFs. This discovery manifested its significance in that it was the first stable bifunctional COF catalyst in water and acidic solution.

a

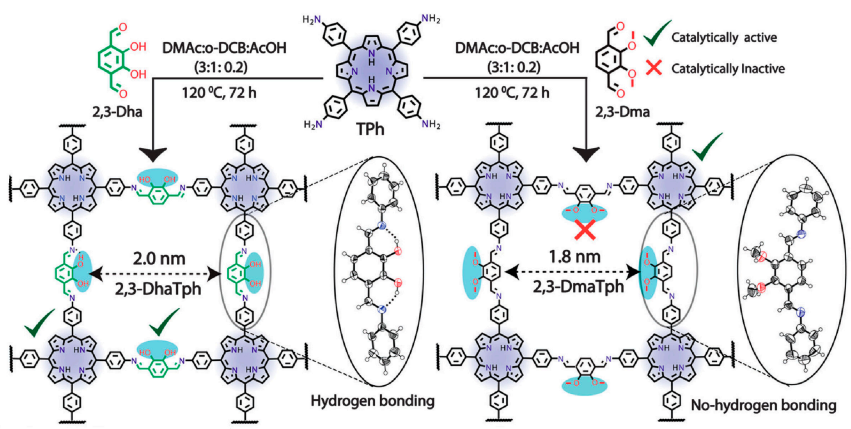

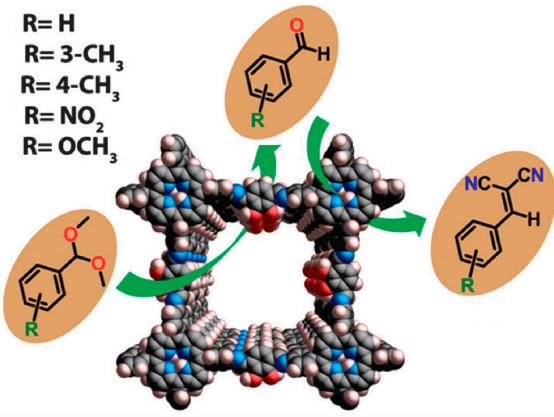

Figure 19. (a) The synthesis of 2,3-DhaTph and 2,3-DmaTph by the condensation of Tph and 2,3-Dha/2,3-Dma. The catalytically active porphyrin and catecholic-OH groups are shown in coral and cyan colors, respectively. An ORTEP diagram of 2,3-DhaTph and 2,3-DmaTph monomer units. (b) The catalytic activity towards acid-base catalyzed reaction with various reactants. Reprinted with permission from [193], Copyright 2015, Royal Society of Chemistry.

Apart from single metal deposited COF materials, bimetallic docked COF materials was designed, synthesized and applied as effective catalysts for a Heck-epoxidation tandem reaction. Mn and Pd bimetallic docking to a bipyridine-imine COF could be realized by a programmed synthetic procedure [194] (see Figure 20). Firstly, a Py-2,2'-BPyPh COF skeleton was constructed via the Schiff-base condensation reaction between $4,4^{\prime}, 4^{\prime \prime}, 4^{\prime \prime \prime}$-(pyrene-1,3,6,8-tetrayl)tetraaniline (PyTTA) and 2,2-bipyridyl-5,5-dialdehyde (2,2'-BPyDCA). The as-formed COF contained two differentiated nitrogen-complexing sites, the bipyridyl and imine units. $\mathrm{MnCl}_{2}$ was docked with bipyridine ligands first, and then $\mathrm{Pd}(\mathrm{OAc})_{2}$ was combined with both bipyridine and imine units. The as-synthesized bimetallic docked COF material acted as effective bifunctional catalyst for two different types of organic transformations, i.e., Pd-catalyzed Heck cross-coupling reaction and Mn-catalyzed epoxidation reaction. The COF material transformed iodobenzene and styrene to trans-stilbene oxide in a tandem reaction. Initially, $\mathrm{Pd}(\mathrm{OAc})$ incorporated in $\mathrm{COF}$ transformed iodobenzene and styrene into trans-stilbene with excellent yield up to $95 \%$, while the $\mathrm{Mn}$ in COF catalyzed the epoxidation reaction of trans-stilbene to trans-stilbene oxide in almost quantitative yield (99\%). The control group experiments proved that Mn@Py-2,2'-BPyPh COF and Pd@Py-2,2'-BPyPh COF alone could only catalyze the separate epoxidation and Heck reaction. This finding was important since it demonstrated that by elaborately design and choose the ligands, different metal species could be incorporated into a single COF skeleton to fulfill different genres of organic transformation by the certain metal.

Besides $\mathrm{Mn}$ and $\mathrm{Pd}$ co-docking for bimetallic COF catalyst, $\mathrm{Rh}$ and $\mathrm{Pd}$ bimetallic docking could also be realized through this 2D BPy COF (see Figure 21) [195]. By condensing $4,4^{\prime}, 4^{\prime \prime}, 4^{\prime \prime \prime}$-(pyrene-1,3,6,8-tetrayl)tetraaniline (PyTTA) and various ratio of X\% 2,2-bipyridyl-5,5-dialdehyde and 100-X\% 4,4'-biphenyldialdehyde in a three-component solvent, a series of structurally tunable $2 \mathrm{D}$ COF were prepared. And the authors demonstrated that by a further solution-infiltration method, $\mathrm{Pd}(\mathrm{OAc})_{2}$ and $\mathrm{Rh}(\mathrm{COD}) \mathrm{Cl}$ was sequentially incorporated into the $\mathrm{COF}$ structure in a programmed synthetic procedure. $\mathrm{Pd}(\mathrm{OAc})_{2}$ dispersed in the interlayer space 
coordinated with both imine units and bipyridine ligands, while the more structurally rigid $\mathrm{Rh}(\mathrm{COD}) \mathrm{Cl}$ deposited in the pore space and complexed with the bipyridine ligands. This $\mathrm{Rh} / \mathrm{Pd}$ bimetallic docked $\mathrm{BPh} \mathrm{COF}$ demonstrated superior catalytic activity towards a tandem addition-oxidation reaction between phenylboronic acid and benzaldehyde to form initially the intermediate diphenylmethanol and further be oxidized to the final product benzophenone. The authors demonstrated that $\mathrm{Rh}(\mathrm{COD}) \mathrm{Cl}$ moiety in COF was accountable for the addition reaction between phenylboronic acid and benzaldehyde surpassing its homogeneous $\mathrm{Rh}(\mathrm{COD}) \mathrm{Cl}$ analogue in catalytic activity. $\mathrm{Pd}(\mathrm{OAc})_{2}$ was responsible for the oxidation from diphenylmethanol to benzophenone. The as-synthesized $\mathrm{Rh} / \mathrm{Pd}-\mathrm{BPh} \mathrm{COF}$ showed excellent recyclability and reusability providing isolated benzophenone products up to $85 \%$ yield even after 5 cycles reuse without noticeable leaching of the metal and apparent loss of activity. This report manifested its significance in that it illustrated that two different kind of organometallic compounds could be docked in a structurally tunable COF material by different coordinating groups to render the COF material different catalytic ability towards totally differentiated reaction types in the first time.
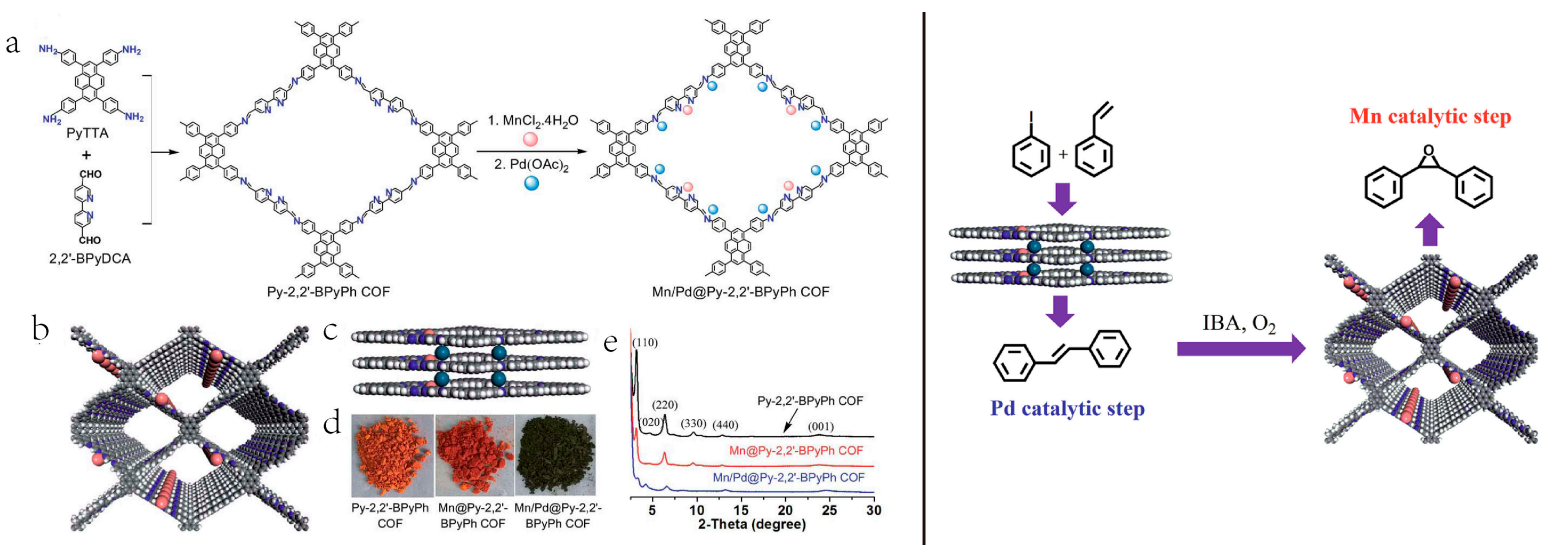

Figure 20. Left, (a) Schematic representation of $\mathrm{Mn} / \mathrm{Pd}$ bimetallic docked COFs prepared via a programmed synthetic procedure; (b) top view and (c) side view of Mn/Pd@py-2,2'-bpy-Ph COF; (d) appearances and (e) PXRD (powder X-ray diffraction) patterns of the COFs before and after metallic loading treatment. Right, Schematic illustration of the tandem reaction catalyzed by Mn/Pd@py-2,2'-bpy-Ph COF.
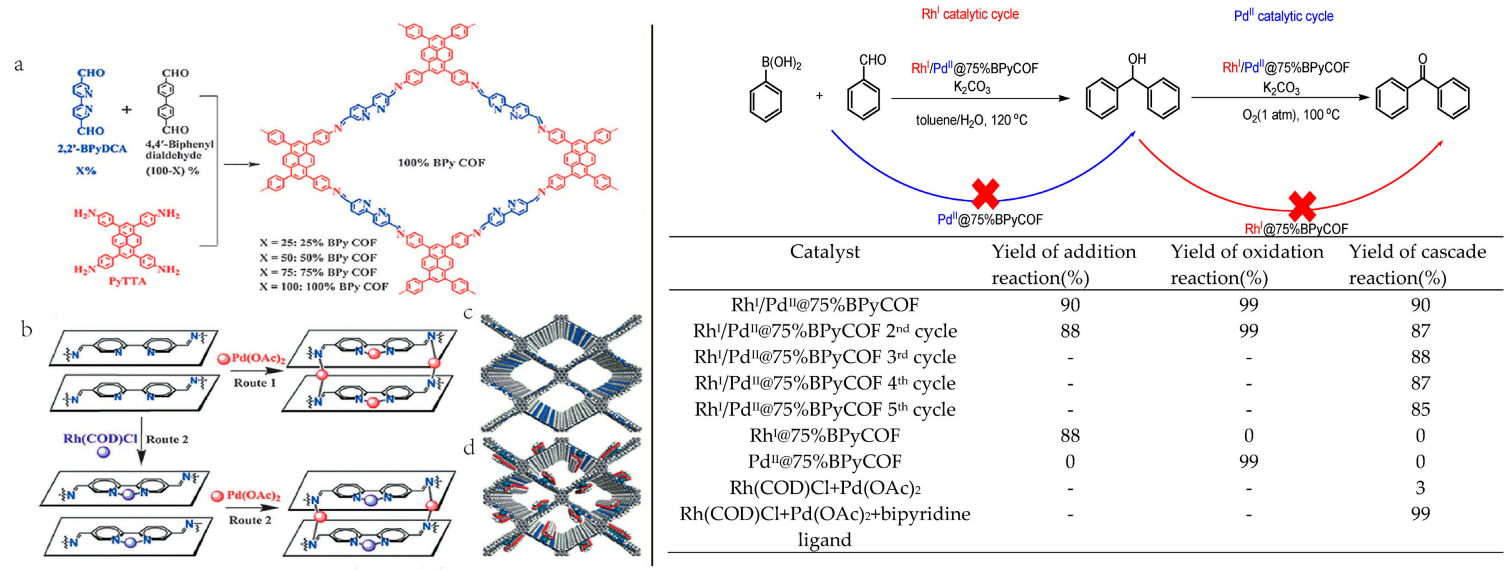

Figure 21. Left, (a) Use of a three-component condensation system to modulate the nitrogen content of the 2D imine-type COFs. (b) Designed strategies for the monometallic (Route 1) and bimetallic docking (Route 2). (c) Open channels of the COFs. (d) Open channels of the metal loaded COFs. Right, One-pot cascade reactions using different homogeneous/heterogeneous catalysts. Reprinted and adapted with permission from [195], Copyright 2016, Wiley. 


\subsection{D COF-Catalyzed C-C Bonds Formations}

Wang et al. described that an interpenetrating dynamic 3D COF LZU-301 could be a Lewis-base catalyst for the Knoevenagel condensation between malonitrile and three aromatic aldehydes [196] (see Figure 22). The authors discovered that for the small size benzaldehyde, the 3D COF LZU-301 provided excellent yield up to $72 \%$ in $4 \mathrm{~h}$ and $99 \%$ in $10 \mathrm{~h}$. However, for the larger 2-naphthalenealdehyde and 9-anthracenealdehyde, the yield notably decreased to $21 \%$ and $5 \%$ due to a size-effect. The larger fuse-ring aromatic aldehyde could not be accommodated into the pore space of LZU-301, thus did not have enough interaction with its pyridine Lewis-base catalytic site, leading to inferior catalytic performance. This example manifested its significance in that it was the only few 3D COFs which demonstrated considerable catalytic activities in meaningful organic synthesis.

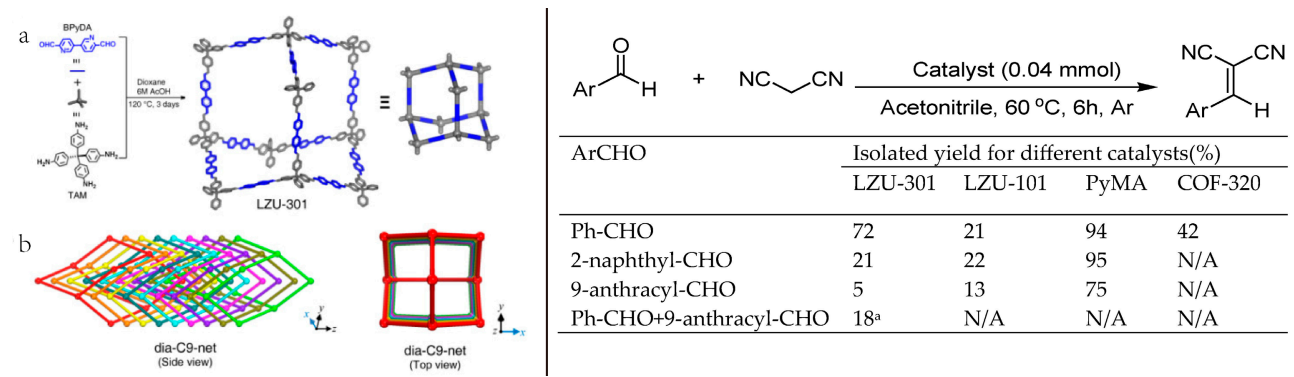

Figure 22. Left, (a) Solvothermal synthesis of a three-dimensional (3D) COF material, LZU-301, via imine condensation. For clarity, only the single framework of LZU-301 is shown. (b) Side and top views of porous crystalline structure of LZU-301, which features with a 9-fold interpenetration of the underlying diamond net. Different color represents different penetrating frameworks from a side-view. Right, Knoevenagel condensation catalytic experiments. ${ }^{a}$ Only $\mathrm{Ph}-\mathrm{CHO}$ reacted with malonitrile under the reaction conditions. Reprinted and adapted with permission from [196], Copyright 2017, American Chemical Society.

Another 3D COF DL-COF-1 and DL-COF-2 was synthesized via the dual linking reaction between 1,3,5,7-tetraaminoadamantane (TAA) and 4-formylphenylboronic acid (FPBA) or 2-fluoro-4-formylphenylboronic acid (FFPBA) forming two kinds of linkage in COF skeleton, namely, boroxine and imine bonds (see Figure 23) [197]. The as-synthesized 3D COFs displayed large specific surface area and incorporated both acidic boroxine sites and basic imine site. These two different sites rendered these $3 \mathrm{D}$ COFs as versatile bifunctional heterogeneous catalyst. To demonstrate its catalytic activity, a one-pot deacetalization-Knoevenagel reaction was applied. DL-COF-1 exhibited excellent yields towards both the acid-catalyzed deacetalization (yield up to $100 \%$ ) and base-catalyzed Knoevenagel condensation reaction (yield up to $98 \%$ ). The COF crystals can be recycled and reused for three times with almost no loss of activity and no identical change in PXRD and $\mathrm{N}_{2}$ uptake characterization. This example was very encouraging since it was the first bifunctional 3D COF with large specific surface area to fulfill heterogeneous catalytic applications.

Qiu et al. reported that 3D imine COF BF-COF-1 and BF-COF-2 could act as effective basic catalyst for C-C formation Knoevenagel reaction (see Figure 24) [135]. These 3D BF-COF-1 and BF-COF-2 materials were synthesized via the imine condensation between 1,3,5,7-tetraaminoadamantane (TAA) and 1,3,5-triformylbenzene (TFB) or triformylphloroglucinol (TFP). The as-formed 3D BF-COF-1 and BF-COF-2 demonstrated excellent size-selection catalytic activity. For small-size reactants, such as benzaldehyde and malonitrile, these 3D COFs exhibited very good conversion up to $99 \%$. However, for the large reactants, which could not be accommodated into the pore space for efficient catalytic interaction, the reaction proceeded much sluggishly with poor yield. To our best knowledge, this was the first catalytic 3D COF materials, which showed excellent size-selection catalytic mode towards base-promoted Knoevenagel condensation. 
a

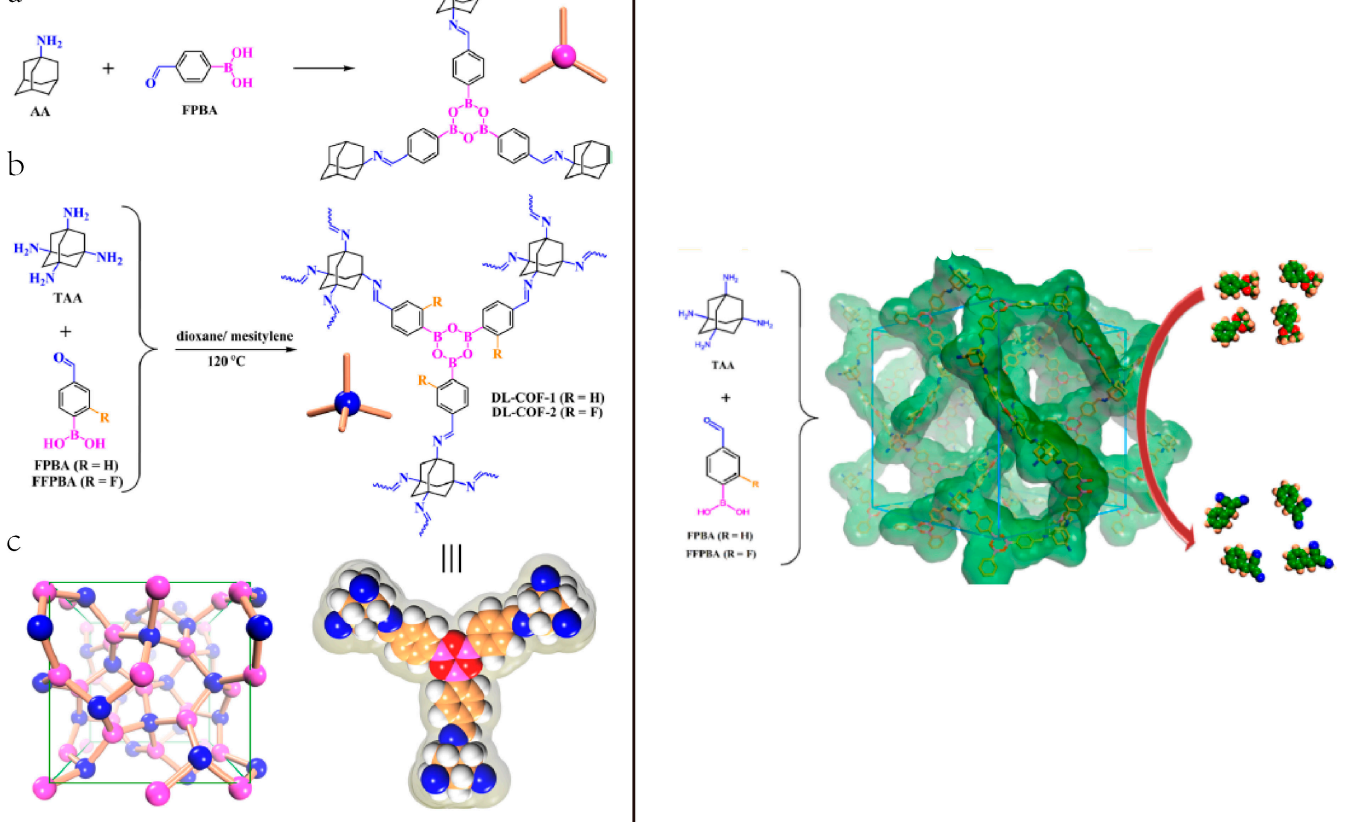

Figure 23. Left, Strategy for preparing 3D COFs with dual linkages (DL-COFs), (a) Model reaction of 1-adamantanamine (AA) with 4-formylphenylboronic acid (FPBA) to form the triangular molecule with dual linkages. (b) Condensation of tetrahedral 1,3,5,7-tetraaminoadamantane (TAA) and FPBA or 2-fluoro-4-formylphenylboronic acid FFPBA) to give 3D COFs with dual linkages, DL-COF-1 or DLCOF-2. (c) On the basis of triangular and tetrahedral building units, both DL-COFs show 3D networks with ctn topology. Right, Three-dimensional COFs with dual linkages for bifunctional cascade catalysis. Reprinted with permission from [197], Copyright 2017, American Chemical Society.

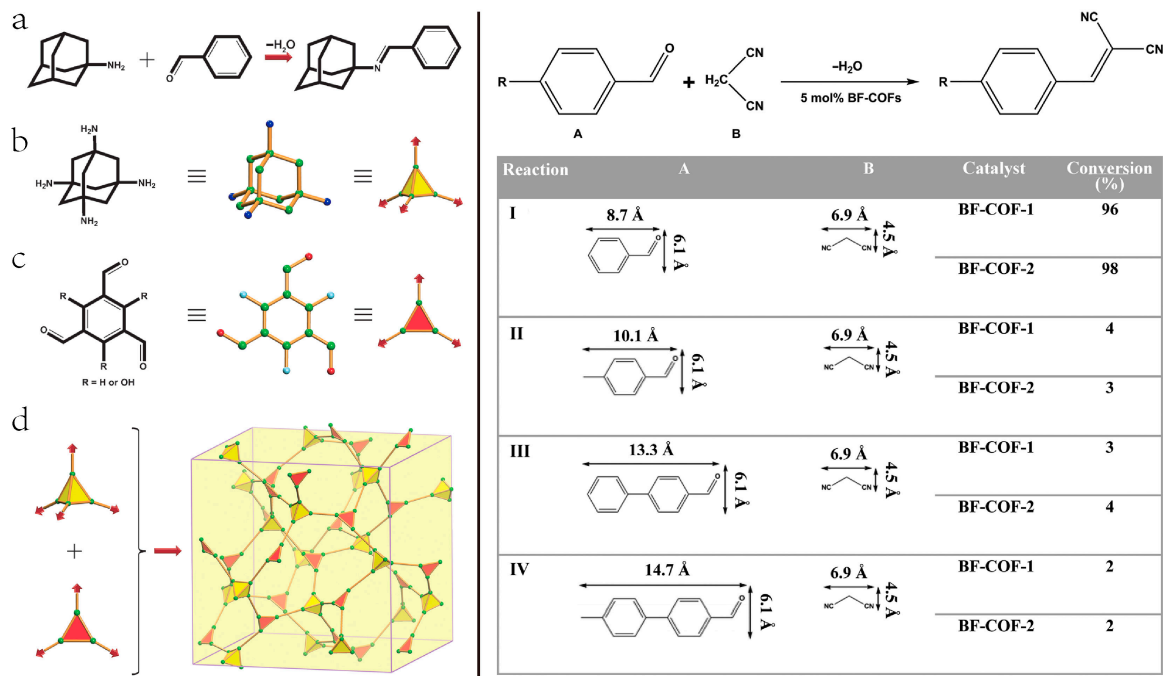

Figure 24. Left, schematic representation of the strategy for preparing 3D microporous base-functionalized COFs. (a) Model reaction of 1-adamantanamine with benzaldehyde to form the molecular N-(1-adamantyl) benzaldehyde imine. (b) Structure of 1,3,5,7-tetraaminoadamantane (TAA) as a tetrahedral building unit. (c) Structure of 1,3,5-triformylbenzene ( $=\mathrm{H}$, TFB) or triformylphloroglucinol ( $\mathrm{R}=\mathrm{OH}, \mathrm{TFP})$ as a triangular building unit. (d) Condensation of tetrahedral and triangular building units to give a 3D network with the symbol ctn (BF-COF-1 or BF-COF-2). Right, Catalytic activity of BF-COFs in the size-selective Knoevenagel condensation reaction. Reprinted with permission from [135], Copyright 2014, Wiley. 
In several C-C coupling reaction such as Knoevenagel condensation, 3D COFs displayed similar high catalytic efficiency as 2D COFs. However, they still differentiate greatly in that 3D COFs catalysis is more sensitive to substrate steric factor. This renders specific 3D COFs the ideal heterogeneous catalyst for size- and shape-dependent catalytic applications.

\section{Conclusions}

We have overviewed the paragon examples of covalent organic frameworks (COFs) applied as heterogeneous catalyst for $\mathrm{C}-\mathrm{C}$ bonds formation reactions. Although in its infancy stage compared with other common catalysts used for C-C bonds formation, such as homogeneous transition-metal catalysts, organocatalysts and enzyme catalysts, COF materials still displayed its multi-faceted advantages. First, metal-loaded COF materials showed parallel or even superior catalytic activity in a series of $\mathrm{C}-\mathrm{C}$ bond formation reactions in contrast with their homogeneous analogues including Heck, Suzuki-Miyaura, Sonogashira cross-coupling, carbon-centered nucleophilic addition and cross-dehydrogenative couplings (CDC). Moreover, COF materials usually demonstrated excellent recyclability and reusability for consecutive runs of catalytic transformations without apparent loss of activity and selectivity. The last but not the least, there appeared some chiral COF (CCOF) materials which showcased powerful control on enantioselectivity in asymmetric organic $\mathrm{C}-\mathrm{C}$ formation events such as asymmetric Michael addition, Henry reaction, Diels-Alder cyclo-addition, $\alpha$-aminooxylation, epoxidation and opening of epoxides. Apart from continuously emerging novel COF structures acting as effective heterogeneous catalysts for $\mathrm{C}-\mathrm{C}$ bond formation reaction in organic synthesis, the new strategy to apply bimetallic and bifunctional COF in catalysis broadens the application fields of COF-based catalysis in more organic reaction types. The new approaches to in-situ loading noble-metal nanoparticles on COF skeleton without requiring external reductants realized the minimal influence and impacts on metal-loading avoiding the decrease of crystallinity and porosity to the least limit. Comparing to homogeneous catalysts, COF-based heterogeneous catalysts still have great space to improve for more challenging reaction types and wider substrate scope for $\mathrm{C}-\mathrm{C}$ bond formation in organic synthesis. The main current limitations and challenges for COFs materials for $\mathrm{C}-\mathrm{C}$ bond formation reaction concentrate on the direct activation of inert $\mathrm{C}-\mathrm{H}$ bonds especially sp $\mathrm{sp}^{3} \mathrm{C}-\mathrm{H}$ bonds to construct $\mathrm{sp}^{3} \mathrm{C}-\mathrm{sp}^{2} \mathrm{C}$ or $\mathrm{sp}^{3} \mathrm{C}-\mathrm{sp}^{3} \mathrm{C}$ bonds. And the activation of energetically important and inert small molecules such as methane, methanol and carbon dioxide for $\mathrm{C}-\mathrm{C}$ bond formation in highly value-added chemicals such as first-line drugs, natural products and organic functional compounds is another developing direction for COFs materials as heterogeneous catalysts. The third one is to developing more metal-free COFs materials acting as highly efficient versatile heterogeneous catalysts for a number of organic synthetic transformations. Comparing to current common homogeneous catalyst, COFs materials demonstrated better recyclability and reusability and lower cost in separating catalyst and the products. However, COFs materials still need to improve their efficiency, selectivity and substrate scopes. Especially, the current catalytic reaction pathways and mechanisms by COFs materials are not clear in comparison with their homogenous analogue. More extensive and deep mechanistic study in COFs materials catalyzed C-C formation reaction need to be conducted in order to further design more efficient and selective catalytic process and more effective COFs catalyst. As the focus frontier of current materials and catalysts research, $\mathrm{COF}$ materials would have brighter prospects for more challenging, meaningful C-C bond formation reaction and more novel principles on COF catalysis would be uncovered along with this promising application field.

Funding: This work was supported by the National Natural Science Foundation of China (21703005), Research Foundation for Youth Scholars of Beijing Technology and Business University (Grant No. QNJJ2017-02) and Support Project of High-level Teachers in Beijing Municipal Universities in the Period of 13th Five-year Plan (CIT\&TCD 201804025).

Conflicts of Interest: The authors declare no conflict of interest. 


\section{References}

1. Diercks, C.S.; Yaghi, O.M. The atom, the molecule, and the covalent organic framework. Science 2017, 355, 923-931. [CrossRef] [PubMed]

2. Stock, N.; Biswas, S. Synthesis of metal-organic frameworks (MOFs): Routes to various MOF topologies, morphologies, and composites. Chem. Rev. 2012, 112, 933-969. [CrossRef] [PubMed]

3. Dhakshinamoorthy, A.; Asiri, A.M.; Garcia, H. Metal-organic framework (MOF) compounds: Photocatalysts for redox reactions and solar fuel production. Angew. Chem. Int. Ed. 2016, 55, 5414-5445. [CrossRef] [PubMed]

4. Li, J.; Corma, A.; Yu, J. Synthesis of new zeolite structures. Chem. Soc. Rev. 2015, 44, 7112-7127. [CrossRef] [PubMed]

5. Li, Y.; Yu, J. New stories of zeolite structures: Their descriptions, determinations, predictions, and evaluations. Chem. Rev. 2014, 114, 7268-7316. [CrossRef] [PubMed]

6. Liang, J.; Liang, Z.; Zou, R.; Zhao, Y. Heterogeneous catalysis in zeolites, mesoporous silica, and metal-organic frameworks. Adv. Mater. 2017, 29, 1701139. [CrossRef] [PubMed]

7. Meng, X.; Xiao, F.S. Green routes for synthesis of zeolites. Chem. Rev. 2014, 114, 1521-1543. [CrossRef] [PubMed]

8. Moeller, K.; Bein, T. Mesoporosity-A new dimension for zeolites. Chem. Soc. Rev. 2013, 42, 3689-3707. [CrossRef] [PubMed]

9. Moliner, M.; Martinez, C.; Corma, A. Multipore zeolites: Synthesis and catalytic applications. Angew. Chem. Int. Ed. 2015, 54, 3560-3579. [CrossRef] [PubMed]

10. Schwieger, W.; Machoke, A.G.; Weissenberger, T.; Inayat, A.; Selvam, T.; Klumpp, M.; Inayat, A. Hierarchy concepts: Classification and preparation strategies for zeolite containing materials with hierarchical porosity. Chem. Soc. Rev. 2016, 45, 3353-3376. [CrossRef] [PubMed]

11. Huang, N.; Wang, P.; Jiang, D. Covalent organic frameworks: A materials platform for structural and functional designs. Nat. Rev. Mater. 2016, 1, 16068. [CrossRef]

12. Jin, Y.; Hu, Y.; Zhang, W. Tessellated multiporous two-dimensional covalent organic frameworks. Nat. Rev. Chem. 2017, 1, 0056. [CrossRef]

13. Tu, W.; Xu, Y.; Yin, S.; Xu, R. Rational design of catalytic centers in crystalline frameworks. Adv. Mater. 2018, 1707582. [CrossRef] [PubMed]

14. Wang, C.A.; Wang, W. Advances in porous organic catalysis. Acta Chim. Sin. 2015, 73, 498-529. [CrossRef]

15. Waller, P.J.; Gandara, F.; Yaghi, O.M. Chemistry of covalent organic frameworks. Acc. Chem. Res. 2015, 48, 3053-3063. [CrossRef] [PubMed]

16. Xiang, Z.; Cao, D. Porous covalent-organic materials: Synthesis, clean energy application and design. J. Mater. Chem. A 2013, 1, 2691-2718. [CrossRef]

17. Tian, J.; Thallapally, P.K.; McGrail, B.P. Porous organic molecular materials. CrystEngComm 2012, 14, 1909-1919. [CrossRef]

18. Thomas, A. Functional materials: From hard to soft porous frameworks. Angew. Chem. Int. Ed. 2010, 49, 8328-8344. [CrossRef] [PubMed]

19. Kaur, P.; Hupp, J.T.; Nguyen, S.T. Porous organic polymers in catalysis: Opportunities and challenges. ACS Catal. 2011, 1, 819-835. [CrossRef]

20. Holst, J.R.; Trewin, A.; Cooper, A.I. Porous organic molecules. Nat. Chem. 2010, 2, 915-920. [CrossRef] [PubMed]

21. Han, S.S.; Furukawa, H.; Yaghi, O.M.; Goddard, W.A., III. Covalent organic frameworks as exceptional hydrogen storage materials. J. Am. Chem. Soc. 2008, 130, 11580-11581. [CrossRef] [PubMed]

22. Furukawa, H.; Yaghi, O.M. Storage of hydrogen, methane, and carbon dioxide in highly porous covalent organic frameworks for clean energy applications. J. Am. Chem. Soc. 2009, 131, 8875-8883. [CrossRef] [PubMed]

23. Doonan, C.J.; Tranchemontagne, D.J.; Glover, T.G.; Hunt, J.R.; Yaghi, O.M. Exceptional ammonia uptake by a covalent organic framework. Nat. Chem. 2010, 2, 235-238. [CrossRef] [PubMed]

24. Ma, H.; Ren, H.; Meng, S.; Yan, Z.; Zhao, H.; Sun, F.; Zhu, G. A 3D microporous covalent organic framework with exceedingly high $\mathrm{C}_{3} \mathrm{H}_{8} / \mathrm{CH}_{4}$ and $\mathrm{C}_{2}$ hydrocarbon/ $\mathrm{CH}_{4}$ selectivity. Chem. Commun. 2013, 49, 9773-9775. [CrossRef] [PubMed] 
25. Adil, K.; Belmabkhout, Y.; Pillai, R.S.; Cadiau, A.; Bhatt, P.M.; Assen, A.H.; Maurin, G.; Eddaoudi, M. Gas/vapour separation using ultra-microporous metal-organic frameworks: Insights into the structure/separation relationship. Chem. Soc. Rev. 2017, 46, 3402-3430. [CrossRef] [PubMed]

26. Cadiau, A.; Adil, K.; Bhatt, P.M.; Belmabkhout, Y.; Eddaoudi, M. A metal-organic framework-based splitter for separating propylene from propane. Science 2016, 353, 137-140. [CrossRef] [PubMed]

27. Trickett, C.A.; Helal, A.; Al-Maythalony, B.A.; Yamani, Z.H.; Cordova, K.E.; Yaghi, O.M. The chemistry of metal-organic frameworks for $\mathrm{CO}_{2}$ capture, regeneration and conversion. Nat. Rev. Mater. 2017, 2, 17045. [CrossRef]

28. Svec, F.; Germain, J.; Frechet, J.M.J. Nanoporous polymers for hydrogen storage. Small 2009, 5, 1098-1111.

29. Patel, H.A.; Je, S.H.; Park, J.; Chen, D.P.; Jung, Y.; Yavuz, C.T.; Coskun, A. Unprecedented high-temperature $\mathrm{CO}_{2}$ selectivity in $\mathrm{N}_{2}$-phobic nanoporous covalent organic polymers. Nat. Commun. 2013, 4, 1357. [CrossRef] [PubMed]

30. DeBlase, C.R.; Dichtel, W.R. Hybrid supercapacitors from framework materials. Chem 2016, 1, 21-23. [CrossRef]

31. DeBlase, C.R.; Hernandez-Burgos, K.; Rotter, J.M.; Fortman, D.J.; dos Abreu, D.S.; Timm, R.A.; Diogenes, I.C.N.; Kubota, L.T.; Abruna, H.D.; Dichtel, W.R. Cation-dependent stabilization of electrogenerated naphthalene diimide dianions in porous polymer thin films and their application to electrical energy storage. Angew. Chem. Int. Ed. 2015, 54, 13225-13229. [CrossRef] [PubMed]

32. DeBlase, C.R.; Silberstein, K.E.; Thanh-Tam, T.; Abruna, H.D.; Dichtel, W.R. Beta-ketoenamine-linked covalent organic frameworks capable of pseudocapacitive energy storage. J. Am. Chem. Soc. 2013, 135, 16821-16824. [CrossRef] [PubMed]

33. $\mathrm{Xu}, \mathrm{H} . ;$ Tao, S.; Jiang, D. Proton conduction in crystalline and porous covalent organic frameworks. Nat. Mater. 2016, 15, 722-726. [CrossRef] [PubMed]

34. Cao, X.; Tan, C.; Sindoro, M.; Zhang, H. Hybrid micro-/nano-structures derived from metal-organic frameworks: Preparation and applications in energy storage and conversion. Chem. Soc. Rev. 2017, 46, 2660-2677. [CrossRef] [PubMed]

35. Guan, B.Y.; Yu, X.Y.; Wu, H.B.; Lou, X.W. Complex nanostructures from materials based on metal-organic frameworks for electrochemical energy storage and conversion. Adv. Mater. 2017, 29, 1703614. [CrossRef] [PubMed]

36. Sheberla, D.; Bachman, J.C.; Elias, J.S.; Sun, C.J.; Shao-Horn, Y.; Dinca, M. Conductive MOF electrodes for stable supercapacitors with high areal capacitance. Nat. Mater. 2017, 16, 220-224. [CrossRef] [PubMed]

37. Salunkhe, R.R.; Kaneti, Y.V.; Kim, J.; Kim, J.H.; Yamauchi, Y. Nanoarchitectures for metal-organic framework-derived nanoporous carbons toward supercapacitor applications. Acc. Chem. Res. 2016, 49, 2796-2806. [CrossRef] [PubMed]

38. Han, Y.; Qi, P.; Feng, X.; Li, S.; Fu, X.; Li, H.; Chen, Y.; Zhou, J.; Li, X.; Wang, B. In situ growth of MOFs on the surface of Si nanoparticles for highly efficient lithium storage: Si@MOF nanocomposites as anode materials for lithium-ion batteries. ACS Appl. Mater. Interfaces 2015, 7, 2178-2182. [CrossRef] [PubMed]

39. Han, Y.; Qi, P.; Li, S.; Feng, X.; Zhou, J.; Li, H.; Su, S.; Li, X.; Wang, B. A novel anode material derived from organic-coated ZIF-8 nanocomposites with high performance in lithium ion batteries. Chem. Commun. 2014, 50, 8057-8060. [CrossRef] [PubMed]

40. Han, Y.; Qi, P.; Zhou, J.; Feng, X.; Li, S.; Fu, X.; Zhao, J.; Yu, D.; Wang, B. Metal-organic frameworks (MOFs) as sandwich coating cushion for silicon anode in lithium ion batteries. ACS Appl. Mater. Interfaces 2015, 7, 26608-26613. [CrossRef] [PubMed]

41. Li, S.; Fu, X.; Zhou, J.; Han, Y.; Qi, P.; Gao, X.; Feng, X.; Wang, B. An effective approach to improve the electrochemical performance of $\mathrm{LiNi}_{0.6} \mathrm{Co}_{0.2} \mathrm{Mn}_{0.2} \mathrm{O}_{2}$ cathode by an MOF-derived coating. J. Mater. Chem. A 2016, 4, 5823-5827. [CrossRef]

42. Qi, P.; Han, Y.; Zhou, J.; Fu, X.; Li, S.; Zhao, J.; Wang, L.; Fan, X.; Feng, X.; Wang, B. Mof derived composites for cathode protection: Coatings of $\mathrm{LiCoO}_{2}$ from UiO-66 and MIL-53 as ultra-stable cathodes. Chem. Commun. 2015, 51, 12391-12394. [CrossRef] [PubMed]

43. Wang, L.; Han, Y.; Feng, X.; Zhou, J.; Qi, P.; Wang, B. Metal-organic frameworks for energy storage: Batteries and supercapacitors. Coord. Chem. Rev. 2016, 307, 361-381. [CrossRef] 
44. Zhou, J.; Li, R.; Fan, X.; Chen, Y.; Han, R.; Li, W.; Zheng, J.; Wang, B.; Li, X. Rational design of a metal-organic framework host for sulfur storage in fast, long-cycle Li-S batteries. Energy Environ. Sci. 2014, 7, 2715-2724. [CrossRef]

45. Zhou, J.; Wang, B. Emerging crystalline porous materials as a multifunctional platform for electrochemical energy storage. Chem. Soc. Rev. 2017, 46, 6927-6945. [CrossRef] [PubMed]

46. Zhou, J.; Yu, X.; Fan, X.; Wang, X.; Li, H.; Zhang, Y.; Li, W.; Zheng, J.; Wang, B.; Li, X. The impact of the particle size of a metal-organic framework for sulfur storage in Li-S. batteries. J. Mater. Chem. A 2015, 3, 8272-8275. [CrossRef]

47. Chandra, S.; Kundu, T.; Kandambeth, S.; BabaRao, R.; Marathe, Y.; Kunjir, S.M.; Banerjee, R. Phosphoric acid loaded azo $(-\mathrm{N}=\mathrm{N}-)$ based covalent organic framework for proton conduction. J. Am. Chem. Soc. 2014, 136, 6570-6573. [CrossRef] [PubMed]

48. Sasmal, H.S.; Aiyappa, H.B.; Bhange, S.N.; Karak, S.; Halder, A.; Kurungot, S.; Banerjee, R. Superprotonic conductivity in flexible porous covalent organic framework membranes. Angew. Chem. Int. Ed. Engl. 2018, 130, 11060-11064. [CrossRef]

49. Jin, S.; Hill, J.P.; Ji, Q.; Shrestha, L.K.; Ariga, K. Supercapacitive hybrid materials from the thermolysis of porous coordination nanorods based on a catechol porphyrin. J. Mater. Chem. A 2016, 4, 5737-5744. [CrossRef]

50. Chandra, S.; Kundu, T.; Dey, K.; Addicoat, M.; Heine, T.; Banerjee, R. Interplaying intrinsic and extrinsic proton conductivities in covalent organic frameworks. Chem. Mater. 2016, 28, 1489-1494. [CrossRef]

51. Horike, S.; Umeyama, D.; Kitagawa, S. Ion conductivity and transport by porous coordination polymers and metal-organic frameworks. Acc. Chem. Res. 2013, 46, 2376-2384. [CrossRef] [PubMed]

52. Yamada, T.; Otsubo, K.; Makiura, R.; Kitagawa, H. Designer coordination polymers: Dimensional crossover architectures and proton conduction. Chem. Soc. Rev. 2013, 42, 6655-6669. [CrossRef] [PubMed]

53. Cui, T.-L.; Ke, W.-Y.; Zhang, W.-B.; Wang, H.-H.; Li, X.-H.; Chen, J.-S. Encapsulating palladium nanoparticles inside mesoporous mfi zeolite nanocrystals for shape-selective catalysis. Angew. Chem. Int. Ed. 2016, 55, 9178-9182. [CrossRef] [PubMed]

54. Dusselier, M.; Davis, M.E. Small-pore zeolites: Synthesis and catalysis. Chem. Rev. 2018, 118, 5265-5329. [CrossRef] [PubMed]

55. Graziano, G. Heterogeneous catalysis: To the zeolite card. Nat. Rev. Chem. 2017, 1, 0037. [CrossRef]

56. Iida, T.; Zanchet, D.; Ohara, K.; Wakihara, T.; Roman-Leshkov, Y. Concerted bimetallic nanocluster synthesis and encapsulation via induced zeolite framework demetallation for shape and substrate selective heterogeneous catalysis. Angew. Chem. Int. Ed. 2018, 57, 6454-6458. [CrossRef] [PubMed]

57. Losch, P.; Hoff, T.C.; Kolb, J.F.; Bernardon, C.; Tessonnier, J.-P.; Louis, B. Mesoporous ZSM-5 zeolites in acid catalysis: Top-down vs. Bottom-up approach. Catalysts 2017, 7, 225. [CrossRef]

58. Martin, A. Zeolite catalysis. Catalysts 2016, 6, 118. [CrossRef]

59. Paolucci, C.; Parekh, A.A.; Khurana, I.; Di Iorio, J.R.; Li, H.; Caballero, J.D.A.; Shih, A.J.; Anggara, T.; Delgass, W.N.; Miller, J.T.; et al. Catalysis in a cage: Condition-dependent speciation and dynamics of exchanged Cu cations in SSZ-13 zeolites. J. Am. Chem. Soc. 2016, 138, 6028-6048. [CrossRef] [PubMed]

60. Wang, N.; Sun, Q.; Bai, R.; Li, X.; Guo, G.; Yu, J. In situ confinement of ultrasmall Pd clusters within nanosized silicalite-1 zeolite for highly efficient catalysis of hydrogen generation. J. Am. Chem. Soc. 2016, 138, 7484-7487. [CrossRef] [PubMed]

61. Zhao, P.; Ye, L.; Sun, Z.; Lo, B.T.W.; Woodcock, H.; Huang, C.; Tang, C.; Kirkland, A.I.; Mei, D.; Tsang, S.C.E. Entrapped single tungstate site in zeolite for cooperative catalysis of olefin metathesis with Brønsted acid site. J. Am. Chem. Soc. 2018, 140, 6661-6667. [CrossRef] [PubMed]

62. Armor, J.N. A history of industrial catalysis. Catal. Today 2011, 163, 3-9. [CrossRef]

63. Choi, M.; Na, K.; Kim, J.; Sakamoto, Y.; Terasaki, O.; Ryoo, R. Stable single-unit-cell nanosheets of zeolite mfi as active and long-lived catalysts. Nature 2009, 461, 246-249. [CrossRef] [PubMed]

64. Choudary, B.M.; Kantam, M.L.; Santhi, P.L. New and ecofriendly options for the production of speciality and fine chemicals. Catal. Today 2000, 57, 17-32. [CrossRef]

65. Degnan, T.F. The implications of the fundamentals of shape selectivity for the development of catalysts for the petroleum and petrochemical industries. J. Catal. 2003, 216, 32-46. [CrossRef]

66. Liu, F.; Huang, K.; Zheng, A.; Xiao, F.-S.; Dai, S. Hydrophobic solid acids and their catalytic applications in green and sustainable chemistry. ACS Catal. 2018, 8, 372-391. [CrossRef] 
67. Ennaert, T.; Van Aelst, J.; Dijkmans, J.; De Clercq, R.; Schutyser, W.; Dusselier, M.; Verboekend, D.; Sels, B.F. Potential and challenges of zeolite chemistry in the catalytic conversion of biomass. Chem. Soc. Rev. 2016, 45, 584-611. [CrossRef] [PubMed]

68. Rangnekar, N.; Mittal, N.; Elyassi, B.; Caro, J.; Tsapatsis, M. Zeolite membranes-A review and comparison with MOFs. Chem. Soc. Rev. 2015, 44, 7128-7154. [CrossRef] [PubMed]

69. Roth, W.J.; Nachtigall, P.; Morris, R.E.; Cejka, J. Two-dimensional zeolites: Current status and perspectives. Chem. Rev. 2014, 114, 4807-4837. [CrossRef] [PubMed]

70. Foo, M.L.; Matsuda, R.; Kitagawa, S. Functional hybrid porous coordination polymers. Chem. Mater. 2014, 26, 310-322. [CrossRef]

71. He, C.; Liu, D.; Lin, W. Nanomedicine applications of hybrid nanomaterials built from metal-ligand coordination bonds: Nanoscale metal-organic frameworks and nanoscale coordination polymers. Chem. Rev. 2015, 115, 11079-11108. [CrossRef] [PubMed]

72. Leong, W.L.; Vittal, J.J. One-dimensional coordination polymers: Complexity and diversity in structures, properties, and applications. Chem. Rev. 2011, 111, 688-764. [CrossRef] [PubMed]

73. Lin, W.; Rieter, W.J.; Taylor, K.M.L. Modular synthesis of functional nanoscale coordination polymers. Angew. Chem. Int. Ed. 2009, 48, 650-658. [CrossRef] [PubMed]

74. Spokoyny, A.M.; Kim, D.; Sumrein, A.; Mirkin, C.A. Infinite coordination polymer nano- and microparticle structures. Chem. Soc. Rev. 2009, 38, 1218-1227. [CrossRef] [PubMed]

75. Zhang, H.; Liu, G.; Shi, L.; Liu, H.; Wang, T.; Ye, J. Engineering coordination polymers for photocatalysis. Nano Energy 2016, 22, 149-168. [CrossRef]

76. Martin, C.F.; Stoeckel, E.; Clowes, R.; Adams, D.J.; Cooper, A.I.; Pis, J.J.; Rubiera, F.; Pevida, C. Hypercrosslinked organic polymer networks as potential adsorbents for pre-combustion $\mathrm{CO}_{2}$ capture. J. Mater. Chem. 2011, 21, 5475-5483. [CrossRef]

77. An, J.; Rosi, N.L. Tuning MOF $\mathrm{CO}_{2}$ adsorption properties via cation exchange. J. Am. Chem. Soc. 2010, 132, 5578-5579. [CrossRef] [PubMed]

78. Furukawa, H.; Miller, M.A.; Yaghi, O.M. Independent verification of the saturation hydrogen uptake in MOF-177 and establishment of a benchmark for hydrogen adsorption in metal-organic frameworks. J. Mater. Chem. 2007, 17, 3197-3204. [CrossRef]

79. Jahan, M.; Bao, Q.; Loh, K.P. Electrocatalytically active graphene-porphyrin mof composite for oxygen reduction reaction. J. Am. Chem. Soc. 2012, 134, 6707-6713. [CrossRef] [PubMed]

80. Kaye, S.S.; Dailly, A.; Yaghi, O.M.; Long, J.R. Impact of preparation and handling on the hydrogen storage properties of $\mathrm{f} \mathrm{Zn}_{4} \mathrm{O}\left(1,4\right.$-benzenedicarboxylate) ${ }_{3}$ (MOF-5). J. Am. Chem. Soc. 2007, 129, 14176-14177. [CrossRef] [PubMed]

81. Liu, Y.; Eubank, J.F.; Cairns, A.J.; Eckert, J.; Kravtsov, V.C.; Luebke, R.; Eddaoudi, M. Assembly of metal-organic frameworks (MOFs) based on indium-trimer building blocks: A porous MOF with soc topology and high hydrogen storage. Angew. Chem. Int. Ed. 2007, 46, 3278-3283. [CrossRef] [PubMed]

82. Shekhah, O.; Liu, J.; Fischer, R.A.; Woell, C. MOF thin films: Existing and future applications. Chem. Soc. Rev. 2011, 40, 1081-1106. [CrossRef] [PubMed]

83. Shultz, A.M.; Farha, O.K.; Hupp, J.T.; Nguyen, S.T. A catalytically active, permanently microporous MOF with metalloporphyrin struts. J. Am. Chem. Soc. 2009, 131, 4204-4205. [CrossRef] [PubMed]

84. Stavila, V.; Talin, A.A.; Allendorf, M.D. MOF-based electronic and optoelectronic devices. Chem. Soc. Rev. 2014, 43, 5994-6010. [CrossRef] [PubMed]

85. Sun, D.F.; Ma, S.Q.; Ke, Y.X.; Collins, D.J.; Zhou, H.C. An interweaving MOF with high hydrogen uptake. J. Am. Chem. Soc. 2006, 128, 3896-3897. [CrossRef] [PubMed]

86. Li, H.; Meng, B.; Chai, S.-H.; Liu, H.; Dai, S. Hyper-crosslinked beta-cyclodextrin porous polymer: An adsorption-facilitated molecular catalyst support for transformation of water-soluble aromatic molecules. Chem. Sci. 2016, 7, 905-909. [CrossRef] [PubMed]

87. Li, H.; Meng, B.; Mahurin, S.M.; Chai, S.-H.; Nelson, K.M.; Baker, D.C.; Liu, H.; Dai, S. Carbohydrate based hyper-crosslinked organic polymers with -OH functional groups for $\mathrm{CO}_{2}$ separation. J. Mater. Chem. A 2015, 3, 20913-20918. [CrossRef]

88. Wang, K.; Huang, L.; Razzaque, S.; Jin, S.; Tan, B. Fabrication of hollow microporous carbon spheres from hyper-crosslinked microporous polymers. Small 2016, 12, 3134-3142. [CrossRef] [PubMed] 
89. Xu, S.; Luo, Y.; Tan, B. Recent development of hypercrosslinked microporous organic polymers. Macromol. Rapid Commun. 2013, 34, 471-484. [CrossRef] [PubMed]

90. Luo, Y.; Li, B.; Wang, W.; Wu, K.; Tan, B. Hypercrosslinked aromatic heterocyclic microporous polymers: A new class of highly selective $\mathrm{CO}_{2}$ capturing materials. Adv. Mater. 2012, 24, 5703-5707. [CrossRef] [PubMed]

91. Li, Q.; Zhan, Z.; Jin, S.; Tan, B. Wettable magnetic hypercrosslinked microporous nanoparticle as an efficient adsorbent for water treatment. Chem. Eng. J. 2017, 326, 109-116. [CrossRef]

92. McKeown, N.B.; Budd, P.M.; Book, D. Microporous polymers as potential hydrogen storage materials. Macromol. Rapid Commun. 2007, 28, 995-1002. [CrossRef]

93. McKeown, N.B.; Budd, P.M. Exploitation of intrinsic microporosity in polymer-based materials. Macromolecules 2010, 43, 5163-5176. [CrossRef]

94. McKeown, N.B.; Budd, P.M. Polymers of intrinsic microporosity (PIMs): Organic materials for membrane separations, heterogeneous catalysis and hydrogen storage. Chem. Soc. Rev. 2006, 35, 675-683. [CrossRef] [PubMed]

95. Mackintosh, H.J.; Budd, P.M.; McKeown, N.B. Catalysis by microporous phthalocyanine and porphyrin network polymers. J. Mater. Chem. 2008, 18, 573-578. [CrossRef]

96. Ghanem, B.S.; McKeown, N.B.; Budd, P.M.; Selbie, J.D.; Fritsch, D. High-performance membranes from polyimides with intrinsic microporosity. Adv. Mater. 2008, 20, 2766-2771. [CrossRef] [PubMed]

97. Budd, P.M.; Elabas, E.S.; Ghanem, B.S.; Makhseed, S.; McKeown, N.B.; Msayib, K.J.; Tattershall, C.E.; Wang, D. Solution-processed, organophilic membrane derived from a polymer of intrinsic microporosity. Adv. Mater. 2004, 16, 456-459. [CrossRef]

98. Chen, Q.; Luo, M.; Hammershoj, P.; Zhou, D.; Han, Y.; Laursen, B.W.; Yan, C.-G.; Han, B.-H. Microporous polycarbazole with high specific surface area for gas storage and separation. J. Am. Chem. Soc. 2012, 134, 6084-6087. [CrossRef] [PubMed]

99. Li, Q.; Razzaque, S.; Jin, S.; Tan, B. Morphology design of microporous organic polymers and their potential applications: An overview. Sci. China Chem. 2017, 60, 1056-1066. [CrossRef]

100. Wang, S.; Zhang, C.; Shu, Y.; Jiang, S.; Xia, Q.; Chen, L.; Jin, S.; Hussain, I.; Cooper, A.I.; Tan, B. Layered microporous polymers by solvent knitting method. Sci. Adv. 2017, 3, e1602610. [CrossRef] [PubMed]

101. Xu, Y.; Jin, S.; Xu, H.; Nagai, A.; Jiang, D. Conjugated microporous polymers: Design, synthesis and application. Chem. Soc. Rev. 2013, 42, 8012-8031. [CrossRef] [PubMed]

102. Jiang, J.-X.; Su, F.; Trewin, A.; Wood, C.D.; Niu, H.; Jones, J.T.A.; Khimyak, Y.Z.; Cooper, A.I. Synthetic control of the pore dimension and surface area in conjugated microporous polymer and copolymer networks. J. Am. Chem. Soc. 2008, 130, 7710-7720. [CrossRef] [PubMed]

103. Dawson, R.; Cooper, A.I.; Adams, D.J. Chemical functionalization strategies for carbon dioxide capture in microporous organic polymers. Polym. Int. 2013, 62, 345-352. [CrossRef]

104. Dawson, R.; Laybourn, A.; Clowes, R.; Khimyak, Y.Z.; Adams, D.J.; Cooper, A.I. Functionalized conjugated microporous polymers. Macromolecules 2009, 42, 8809-8816. [CrossRef]

105. Cooper, A.I. Conjugated microporous polymers. Adv. Mater. 2009, 21, 1291-1295. [CrossRef]

106. Cote, A.P.; Benin, A.I.; Ockwig, N.W.; O’Keeffe, M.; Matzger, A.J.; Yaghi, O.M. Porous, crystalline, covalent organic frameworks. Science 2005, 310, 1166-1170. [CrossRef] [PubMed]

107. El-Kaderi, H.M.; Hunt, J.R.; Mendoza-Cortes, J.L.; Cote, A.P.; Taylor, R.E.; O’Keeffe, M.; Yaghi, O.M. Designed Synthesis of 3D Covalent Organic Frmaeworks. Science 2007, 316, 268-272. [CrossRef] [PubMed]

108. Lin, S.; Diercks, C.S.; Zhang, Y.-B.; Kornienko, N.; Nichols, E.M.; Zhao, Y.; Paris, A.R.; Kim, D.; Yang, P.; Yaghi, O.M.; et al. Covalent organic frameworks comprising cobalt porphyrins for catalytic $\mathrm{CO}_{2}$ reduction in water. Science 2015, 349, 1208-1213. [CrossRef] [PubMed]

109. Liu, Y.; Ma, Y.; Zhao, Y.; Sun, X.; Gandara, F.; Furukawa, H.; Liu, Z.; Zhu, H.; Zhu, C.; Suenaga, K.; et al. Weaving of organic threads into a crystalline covalent organic framework. Science 2016, 351, 365-369. [CrossRef] [PubMed]

110. Ma, T.; Kapustin, E.A.; Yin, S.X.; Liang, L.; Zhou, Z.; Niu, J.; Li, L.-H.; Wang, Y.; Su, J.; Li, J.; et al. Single-crystal x-ray diffraction structures of covalent organic frameworks. Science 2018, 361, 48-52. [CrossRef] [PubMed]

111. Biswal, B.P.; Chandra, S.; Kandambeth, S.; Lukose, B.; Heine, T.; Banerjeet, R. Mechanochemical synthesis of chemically stable isoreticular covalent organic frameworks. J. Am. Chem. Soc. 2013, 135, 5328-5331. [CrossRef] [PubMed] 
112. Biswal, B.P.; Chaudhari, H.D.; Banerjee, R.; Kharul, U.K. Chemically stable covalent organic framework (COF)-polybenzimidazole hybrid membranes: Enhanced gas separation through pore modulation. Chem. Eur. J. 2016, 22, 4695-4699. [CrossRef] [PubMed]

113. Biswal, B.P.; Kandambeth, S.; Chandra, S.; Shinde, D.B.; Bera, S.; Karak, S.; Garai, B.; Kharul, U.K.; Banerjee, R. Pore surface engineering in porous, chemically stable covalent organic frameworks for water adsorption. J. Mater. Chem. A 2015, 3, 23664-23669. [CrossRef]

114. Chandra, S.; Kandambeth, S.; Biswal, B.P.; Lukose, B.; Kunjir, S.M.; Chaudhary, M.; Babarao, R.; Heine, T.; Banerjee, R. Chemically stable multilayered covalent organic nanosheets from covalent organic frameworks via mechanical delamination. J. Am. Chem. Soc. 2013, 135, 17853-17861. [CrossRef] [PubMed]

115. Kandambeth, S.; Mallick, A.; Lukose, B.; Mane, M.V.; Heine, T.; Banerjee, R. Construction of crystalline 2D covalent organic frameworks with remarkable chemical (acid/base) stability via a combined reversible and irreversible route. J. Am. Chem. Soc. 2012, 134, 19524-19527. [CrossRef] [PubMed]

116. Kandambeth, S.; Venkatesh, V.; Shinde, D.B.; Kumari, S.; Halder, A.; Verma, S.; Banerjee, R. Self-templated chemically stable hollow spherical covalent organic framework. Nat. Commun. 2015, 6, 6786. [CrossRef] [PubMed]

117. Pachfule, P.; Kandambeth, S.; Diaz, D.D.; Banerjee, R. Highly stable covalent organic framework-Au nanoparticles hybrids for enhanced activity for nitrophenol reduction. Chem. Commun. 2014, 50, 3169-3172. [CrossRef] [PubMed]

118. Ding, S.-Y.; Gao, J.; Wang, Q.; Zhang, Y.; Song, W.-G.; Su, C.-Y.; Wang, W. Construction of covalent organic framework for catalysis: Pd/COF-LZU1 in Suzuki-Miyaura coupling reaction. J. Am. Chem. Soc. 2011, 133, 19816-19822. [CrossRef] [PubMed]

119. Rao, M.R.; Fang, Y.; De Feyter, S.; Perepichka, D.F. Conjugated covalent organic frameworks via Michael addition-elimination. J. Am. Chem. Soc. 2017, 139, 2421-2427. [CrossRef] [PubMed]

120. Wan, S.; Guo, J.; Kim, J.; Thee, H.; Jiang, D.A. belt-shaped, blue luminescent, and semiconducting covalent organic framework. Angew. Chem. Int. Ed. 2008, 47, 8826-8830. [CrossRef] [PubMed]

121. Dalapati, S.; Jin, E.; Addicoat, M.; Heine, T.; Jiang, D. Highly emissive covalent organic frameworks. J. Am. Chem. Soc. 2016, 138, 5797-5800. [CrossRef] [PubMed]

122. Dalapati, S.; Jin, S.; Gao, J.; Xu, Y.; Nagai, A.; Jiang, D. An azine-linked covalent organic framework. J. Am. Chem. Soc. 2013, 135, 17310-17313. [CrossRef] [PubMed]

123. Wan, S.; Guo, J.; Kim, J.; Ihee, H.; Jiang, D. A photoconductive covalent organic framework: Self-condensed arene cubes composed of eclipsed 2D polypyrene sheets for photocurrent generation. Angew. Chem. Int. Ed. 2009, 48, 5439-5442. [CrossRef] [PubMed]

124. Ding, X.; Guo, J.; Feng, X.; Honsho, Y.; Guo, J.; Seki, S.; Maitarad, P.; Saeki, A.; Nagase, S.; Jiang, D. Synthesis of metallophthalocyanine covalent organic frameworks that exhibit high carrier mobility and photoconductivity. Angew. Chem. Int. Ed. 2011, 50, 1289-1293. [CrossRef] [PubMed]

125. Dogru, M.; Handloser, M.; Auras, F.; Kunz, T.; Medina, D.; Hartschuh, A.; Knochel, P.; Bein, T. A photoconductive thienothiophene-based covalent organic framework showing charge transfer towards included fullerene. Angew. Chem. Int. Ed. 2013, 52, 2920-2924. [CrossRef] [PubMed]

126. Guo, J.; Xu, Y.; Jin, S.; Chen, L.; Kaji, T.; Honsho, Y.; Addicoat, M.A.; Kim, J.; Saeki, A.; Ihee, H.; et al. Conjugated organic framework with three-dimensionally ordered stable structure and delocalized Pi clouds. Nat. Commun. 2013, 4, 2736. [CrossRef] [PubMed]

127. Spitler, E.L.; Colson, J.W.; Uribe-Romo, F.J.; Woll, A.R.; Giovino, M.R.; Saldivar, A.; Dichtel, W.R. Lattice expansion of highly oriented 2D phthalocyanine covalent organic framework films. Angew. Chem. Int. Ed. 2012, 51, 2623-2627. [CrossRef] [PubMed]

128. Spitler, E.L.; Dichtel, W.R. Lewis acid-catalysed formation of two-dimensional phthalocyanine covalent organic frameworks. Nat. Chem. 2010, 2, 672-677. [CrossRef] [PubMed]

129. Banerjee, T.; Gottschling, K.; Savasci, G.; Ochsenfeld, C.; Lotsch, B.V. $\mathrm{H}_{2}$ evolution with covalent organic framework photocatalysts. ACS Energy Lett. 2018, 3, 400-409. [CrossRef] [PubMed]

130. Banerjee, T.; Haase, F.; Savasci, G.; Gottschling, K.; Ochsenfeld, C.; Lotsch, B.V. Single-site photocatalytic $\mathrm{H}_{2}$ evolution from covalent organic frameworks with molecular cobaloxime co-catalysts. J. Am. Chem. Soc. 2017, 139, 16228-16234. [CrossRef] [PubMed] 
131. Haase, F.; Banerjee, T.; Savasci, G.; Ochsenfeld, C.; Lotsch, B.V. Structure-property-activity relationships in a pyridine containing azine-linked covalent organic framework for photocatalytic hydrogen evolution. Faraday Discuss. 2017, 201, 259-276. [CrossRef] [PubMed]

132. Stegbauer, L.; Schwinghammer, K.; Lotsch, B.V. A hydrazone-based covalent organic framework for photocatalytic hydrogen production. Chem. Sci. 2014, 5, 2789-2793. [CrossRef]

133. Vyas, V.S.; Haase, F.; Stegbauer, L.; Savasci, G.; Podjaski, F.; Ochsenfeld, C.; Lotsch, B.V. A tunable azine covalent organic framework platform for visible light-induced hydrogen generation. Nat. Commun. 2015, 6, 8508. [CrossRef] [PubMed]

134. Zhang, Y.-B.; Su, J.; Furukawa, H.; Yun, Y.; Gandara, F.; Duong, A.; Zou, X.; Yaghi, O.M. Single-crystal structure of a covalent organic framework. J. Am. Chem. Soc. 2013, 135, 16336-16339. [CrossRef] [PubMed]

135. Fang, Q.; Gu, S.; Zheng, J.; Zhuang, Z.; Qiu, S.; Yan, Y. 3D microporous base-functionalized covalent organic frameworks for size-selective catalysis. Angew. Chem. Int. Ed. 2014, 53, 2878-2882. [CrossRef] [PubMed]

136. Klontzas, E.; Tylianakis, E.; Froudakis, G.E. Hydrogen storage in 3D covalent organic frameworks: A multiscale theoretical investigation. J. Phys. Chem. C 2008, 112, 9095-9098. [CrossRef]

137. Klontzas, E.; Tylianakis, E.; Froudakis, G.E. Designing 3D COFs with enhanced hydrogen storage capacity. Nano Lett. 2010, 10, 452-454. [CrossRef] [PubMed]

138. Diercks, C.S.; Lin, S.; Komienko, N.; Kapustin, E.A.; Nichols, E.M.; Zhu, C.; Zhao, Y.; Chang, C.J.; Yaghi, O.M. Reticular electronic tuning of porphyrin active sites in covalent organic frameworks for electrocatalytic carbon dioxide reduction. J. Am. Chem. Soc. 2018, 140, 1116-1122. [CrossRef] [PubMed]

139. Yadav, R.K.; Baeg, J.-O.; Oh, G.H.; Park, N.-J.; Kong, K.-J.; Kim, J.; Hwang, D.W.; Biswas, S.K. A photocatalyst-enzyme coupled artificial photosynthesis system for solar energy in production of formic acid from $\mathrm{CO}_{2}$. J. Am. Chem. Soc. 2012, 134, 11455-11461. [CrossRef] [PubMed]

140. Gunasekar, G.H.; Park, K.; Ganesan, V.; Lee, K.; Kim, N.-K.; Jung, K.-D.; Yoon, S. A covalent triazine framework, functionalized with $\mathrm{Ir} / \mathrm{N}$-heterocyclic carbene sites, for the efficient hydrogenation of $\mathrm{CO}_{2}$ to formate. Chem. Mater. 2017, 29, 6740-6748. [CrossRef]

141. Lin, C.-Y.; Zhang, D.; Zhao, Z.; Xia, Z. Covalent organic framework electrocatalysts for clean energy conversion. Adv. Mater. 2018, 30, 1703646. [CrossRef] [PubMed]

142. Lin, C.-Y.; Zhang, L.; Zhao, Z.; Xia, Z. Design principles for covalent organic frameworks as efficient electrocatalysts in clean energy conversion and green oxidizer production. Adv. Mater. 2017, 29, 1606635. [CrossRef] [PubMed]

143. Pachfule, P.; Acharjya, A.; Roeser, J.; Langenhahn, T.; Schwarze, M.; Schomaecker, R.; Thomas, A.; Schmidt, J. Diacetylene functionalized covalent organic framework (COF) for photocatalytic hydrogen generation. J. Am. Chem. Soc. 2018, 140, 1423-1427. [CrossRef] [PubMed]

144. Zhou, Y.; Xiang, Z.; Cao, D.; Liu, C.-J. Preparation and characterization of covalent organic polymer supported palladium catalysts for oxidation of CO and benzyl alcohol. Ind. Eng. Chem. Res. 2014, 53, 1359-1367. [CrossRef]

145. Zhao, M.; Wu, C.-D. Synthesis and post-metalation of a covalent-porphyrinic framework for highly efficient aerobic epoxidation of olefins. Catal. Commun. 2017, 99, 146-149. [CrossRef]

146. Zhang, W.; Jiang, P.; Wang, Y.; Zhang, J.; Zhang, P. Bottom-up approach to engineer two covalent porphyrinic frameworks as effective catalysts for selective oxidation. Catal. Sci. Technol. 2015, 5, 101-104. [CrossRef]

147. Zhang, W.; Jiang, P.; Wang, Y.; Zhang, J.; Gao, Y.; Zhang, P. Bottom-up approach to engineer a molybdenum-doped covalent-organic framework catalyst for selective oxidation reaction. RSC Adv. 2014, 4, 51544-51547. [CrossRef]

148. Wei, P.-F.; Qi, M.-Z.; Wang, Z.-P.; Ding, S.-Y.; Yu, W.; Liu, Q.; Wang, L.-K.; Wang, H.-Z.; An, W.-K.; Wang, W. Benzoxazole-linked ultrastable covalent organic frameworks for photocatalysis. J. Am. Chem. Soc. 2018, 140, 4623-4631. [CrossRef] [PubMed]

149. Palkovits, R.; Antonietti, M.; Kuhn, P.; Thomas, A.; Schueth, F. Solid catalysts for the selective low-temperature oxidation of methane to methanol. Angew. Chem. Int. Ed. 2009, 48, 6909-6912. [CrossRef] [PubMed]

150. Mu, M.; Wang, Y.; Qin, Y.; Yan, X.; Li, Y.; Chen, L. Two-dimensional imine-linked covalent organic frameworks as a platform for selective oxidation of olefins. ACS Appl. Mater. Interfaces 2017, 9, 22856-22863. [CrossRef] [PubMed] 
151. Huang, W.; Ma, B.C.; Lu, H.; Li, R.; Wang, L.; Landfester, K.; Zhang, K.A.I. Visible-light-promoted selective oxidation of alcohols using a covalent triazine framework. ACS Catal. 2017, 7, 5438-5442. [CrossRef]

152. Gao, W.; Sun, X.; Niu, H.; Song, X.; Li, K.; Gao, H.; Zhang, W.; Yu, J.; Jia, M. Phosphomolybdic acid functionalized covalent organic frameworks: Structure characterization and catalytic properties in olefin epoxidation. Microporous Mesoporous Mater. 2015, 213, 59-67. [CrossRef]

153. Chan-Thaw, C.E.; Villa, A.; Katekomol, P.; Su, D.; Thomas, A.; Prati, L. Covalent triazine framework as catalytic support for liquid phase reaction. Nano Lett. 2010, 10, 537-541. [CrossRef] [PubMed]

154. Wang, X.S.; Chrzanowski, M.; Yuan, D.; Sweeting, B.S.; Ma, S. Covalent heme framework as a highly active heterogeneous biomimetic oxidation catalyst. Chem. Mater. 2014, 26, 1639-1644. [CrossRef]

155. Chan-Thaw, C.E.; Villa, A.; Prati, L.; Thomas, A. Triazine-based polymers as nanostructured supports for the liquid-phase oxidation of alcohols. Chem. Eur. J. 2011, 17, 1052-1057. [CrossRef] [PubMed]

156. Bavykina, A.V.; Olivos-Suarez, A.I.; Osadchii, D.; Valecha, R.; Franz, R.; Makkee, M.; Kapteijn, F.; Gascon, J. Facile method for the preparation of covalent triazine framework coated monoliths as catalyst support: Applications in $\mathrm{C}_{1}$ catalysis. ACS Appl. Mater. Interfaces 2017, 9, 26060-26065. [CrossRef] [PubMed]

157. Artz, J.; Mallmann, S.; Palkovits, R. Selective aerobic oxidation of HMF to 2,5-diformylfuran on covalent triazine frameworks-supported Ru catalysts. ChemSusChem 2015, 8, 672-679. [CrossRef] [PubMed]

158. Chen, G.J.; Li, X.B.; Zhao, C.C.; Ma, H.C.; Kan, J.L.; Xin, Y.B.; Chen, C.X.; Dong, Y.B. Ru nanoparticles-loaded covalent organic framework for solvent-free one-pot tandem reactions in air. Inorg. Chem. 2018, 57, 2678-2685. [CrossRef] [PubMed]

159. Shi, X.; Yao, Y.; Xu, Y.; Liu, K.; Zhu, G.; Chi, L.; Lu, G. Imparting catalytic activity to a covalent organic framework material by nanoparticle encapsulation. ACS Appl. Mater. Interfaces 2017, 9, 7481-7488. [CrossRef] [PubMed]

160. Ding, Z.D.; Wang, Y.X.; Xi, S.F.; Li, Y.; Li, Z.; Ren, X.; Gu, Z.G. A hexagonal covalent porphyrin framework as an efficient support for gold nanoparticles toward catalytic reduction of 4-nitrophenol. Chem. Eur. J. 2016, 22, 17027-17034. [CrossRef] [PubMed]

161. Sun, Q.; Aguila, B.; Perman, J.; Nguyen, N.; Ma, S. Flexibility matters: Cooperative active sites in covalent organic framework and threaded ionic polymer. J. Am. Chem. Soc. 2016, 138, 15790-15796. [CrossRef] [PubMed]

162. Roeser, J.; Kailasam, K.; Thomas, A. Covalent triazine frameworks as heterogeneous catalysts for the synthesis of cyclic and linear carbonates from carbon dioxide and epoxides. ChemSusChem 2012, 5, 1793-1799. [CrossRef] [PubMed]

163. Liu, G.; Sheng, J.; Zhao, Y. Chiral covalent organic frameworks for asymmetric catalysis and chiral separation. Sci. China Chem. 2017, 60, 1015-1022. [CrossRef]

164. Santoro, S.; Kozhushkov, S.I.; Ackermann, L.; Vaccaro, L. Heterogeneous catalytic approaches in C-H activation reactions. Green Chem. 2016, 18, 3471-3493. [CrossRef]

165. Ma, D.; Liu, A.; Li, S.; Lu, C.; Chen, C. $\mathrm{TiO}_{2}$ photocatalysis for C-C. bond formation. Catal. Sci. Technol. 2018, 8, 2030-2045. [CrossRef]

166. Ma, D.; Liu, A.; Lu, C.; Chen, C. Photocatalytic dehydrogenation of primary alcohols: Selectivity goes against adsorptivity. ACS Omega 2017, 2, 4161-4172. [CrossRef]

167. Ma, D.; Yan, Y.; Ji, H.W.; Chen, C.C.; Zhao, J.C. Photocatalytic activation of pyridine for addition reactions: An unconventional reaction feature between a photo-induced hole and electron on $\mathrm{TiO}_{2}$. Chem. Commun. 2015, 51, 17451-17454. [CrossRef] [PubMed]

168. Wang, Y.; Liu, A.; Ma, D.; Li, S.; Lu, C.; Li, T.; Chen, C. $\mathrm{TiO}_{2}$ photocatalyzed C-H bond transformation for C.C. coupling reactions. Catalysts 2018, 8, 355. [CrossRef]

169. Hu, H.; Yan, Q.; Ge, R.; Gao, Y. Covalent organic frameworks as heterogeneous catalysts. Chin. J. Catal. 2018, 39, 1167-1179. [CrossRef]

170. Fu, X.; Yu, G. Covalent organic frameworks catalysts. Prog. Chem. 2016, 28, 1006-1015.

171. Beletskaya, I.P.; Cheprakov, A.V. The Heck reaction as a sharpening stone of palladium catalysis. Chem. Rev. 2000, 100, 3009-3066. [CrossRef] [PubMed]

172. Takemoto, T.; Iwasa, S.; Hamada, H.; Shibatomi, K.; Kameyama, M.; Motoyama, Y.; Nishiyama, H. Highly efficient Suzuki-Miyaura coupling reactions catalyzed by bis(oxazolinyl)phenyl-Pd(II) complex. Tetrahedron Lett. 2007, 48, 3397-3401. [CrossRef] 
173. Ozawa, F.; Kubo, A.; Hayashi, T. Catalytic Asymmetric Heck Reaction. In Selectivity in Catalysis; ACS Symposium Series 517; American Chemical Society: Washington, DC, USA, 1993; Volume 517, pp. $75-85$.

174. Kamei, T.; Sato, A.H.; Iwasawa, T. Asymmetric Suzuki-Miyaura cross-coupling of aryl chlorides with enhancement of reaction time and catalyst turnover. Tetrahedron Lett. 2011, 52, 2638-2641. [CrossRef]

175. Hou, Y.; Zhang, X.; Sun, J.; Lin, S.; Qi, D.; Hong, R.; Li, D.; Xiao, X.; Jiang, J. Good Suzuki-coupling reaction performance of Pd immobilized at the metal-free porphyrin-based covalent organic framework. Microporous Mesoporous Mater. 2015, 214, 108-114. [CrossRef]

176. Llabres i Xamena, F.X.; Abad, A.; Corma, A.; Garcia, H. MOFs as catalysts: Activity, reusability and shape-selectivity of a Pd-containing mof. J. Catal. 2007, 250, 294-298. [CrossRef]

177. Mullangi, D.; Nandi, S.; Shalini, S.; Sreedhala, S.; Vinod, C.P.; Vaidhyanathan, R. Pd loaded amphiphilic COF as catalyst for multi-fold Heck reactions, C-C couplings and CO oxidation. Sci. Rep. 2015, 5, 10876. [CrossRef] [PubMed]

178. Kaleeswaran, D.; Antony, R.; Sharma, A.; Malani, A.; Murugavel, R. Catalysis and $\mathrm{CO}_{2}$ capture by palladium-incorporated covalent organic frameworks. Chempluschem 2017, 82, 1253-1265. [CrossRef]

179. Lu, S.; Hu, Y.; Wan, S.; McCaffrey, R.; Jin, Y.; Gu, H.; Zhang, W. Synthesis of ultrafine and highly dispersed metal nanoparticles confined in a thioether-containing covalent organic framework and their catalytic applications. J. Am. Chem. Soc. 2017, 139, 17082-17088. [CrossRef] [PubMed]

180. Pachfule, P.; Panda, M.K.; Kandambeth, S.; Shivaprasad, S.M.; Diaz Diaz, D.; Banerjee, R. Multifunctional and robust covalent organic framework-nanoparticle hybrids. J. Mater. Chem. A 2014, 2, 7944-7952. [CrossRef]

181. Zhang, J.; Peng, Y.; Leng, W.; Gao, Y.; Xu, F.; Chai, J. Nitrogen ligands in two-dimensional covalent organic frameworks for metal catalysis. Chin. J. Catal. 2016, 37, 468-475. [CrossRef]

182. Bhadra, M.; Sasmal, H.S.; Basu, A.; Midya, S.P.; Kandambeth, S.; Pachfule, P.; Balaraman, E.; Banerjee, R. Predesigned metal-anchored building block for in situ generation of Pd nanoparticles in porous covalent organic framework: Application in heterogeneous tandem catalysis. ACS Appl. Mater. Interfaces 2017, 9, 13785-13792. [CrossRef] [PubMed]

183. Lin, S.; Hou, Y.; Deng, X.; Wang, H.; Sun, S.; Zhang, X. A triazine-based covalent organic framework/palladium hybrid for one-pot silicon-based cross-coupling of silanes and aryl iodides. RSC Adv. 2015, 5, 41017-41024. [CrossRef]

184. Liu, W.; Su, Q.; Ju, P.; Guo, B.; Zhou, H.; Li, G.; Wu, Q. A hydrazone-based covalent organic framework as an efficient and reusable photocatalyst for the cross-dehydrogenative coupling reaction of N-aryltetrahydroisoquinolines. ChemSusChem 2017, 10, 664-669. [CrossRef] [PubMed]

185. Zhi, Y.; Li, Z.; Feng, X.; Xia, H.; Zhang, Y.; Shi, Z.; Mu, Y.; Liu, X. Covalent organic frameworks as metal-free heterogeneous photocatalysts for organic transformations. J. Mater. Chem. A 2017, 5, 22933-22938. [CrossRef]

186. Xu, H.; Chen, X.; Gao, J.; Lin, J.; Addicoat, M.; Irle, S.; Jiang, D. Catalytic covalent organic frameworks via pore surface engineering. Chem. Commun. 2014, 50, 1292-1294. [CrossRef] [PubMed]

187. Xu, H.; Gao, J.; Jiang, D. Stable, crystalline, porous, covalent organic frameworks as a platform for chiral organocatalysts. Nat. Chem. 2015, 7, 905-912. [CrossRef] [PubMed]

188. Ma, H.C.; Kan, J.L.; Chen, G.J.; Chen, C.X.; Dong, Y.B. Pd NPs-loaded homochiral covalent organic framework for heterogeneous asymmetric catalysis. Chem. Mater. 2017, 29, 6518-6524. [CrossRef]

189. Zhang, J.; Han, X.; Wu, X.; Liu, Y.; Cui, Y. Multivariate chiral covalent organic frameworks with controlled crystallinity and stability for asymmetric catalysis. J. Am. Chem. Soc. 2017, 139, 8277-8285. [CrossRef] [PubMed]

190. Wang, X.; Han, X.; Zhang, J.; Wu, X.; Liu, Y.; Cui, Y. Homochiral 2D porous covalent organic frameworks for heterogeneous asymmetric catalysis. J. Am. Chem. Soc. 2016, 138, 12332-12335. [CrossRef] [PubMed]

191. Han, X.; Xia, Q.; Huang, J.; Liu, Y.; Tan, C.; Cui, Y. Chiral covalent organic frameworks with high chemical stability for heterogeneous asymmetric catalysis. J. Am. Chem. Soc. 2017, 139, 8693-8697. [CrossRef] [PubMed]

192. Xu, H.S.; Ding, S.Y.; An, W.K.; Wu, H.; Wang, W. Constructing crystalline covalent organic frameworks from chiral building blocks. J. Am. Chem. Soc. 2016, 138, 11489-11492. [CrossRef] [PubMed]

193. Shinde, D.B.; Kandambeth, S.; Pachfule, P.; Kumar, R.R.; Banerjee, R. Bifunctional covalent organic frameworks with two dimensional organocatalytic micropores. Chem. Commun. 2015, 51, 310-313. [CrossRef] [PubMed] 
194. Leng, W.; Ge, R.; Dong, B.; Wang, C.; Gao, Y. Bimetallic docked covalent organic frameworks with high catalytic performance towards tandem reactions. RSC Adv. 2016, 6, 37403-37406. [CrossRef]

195. Leng, W.; Peng, Y.; Zhang, J.; Lu, H.; Feng, X.; Ge, R.; Dong, B.; Wang, B.; Hu, X.; Gao, Y. Sophisticated design of covalent organic frameworks with controllable bimetallic docking for a cascade reaction. Chem. Eur. J. 2016, 22, 9087-9091. [CrossRef] [PubMed]

196. Ma, Y.X.; Li, Z.J.; Wei, L.; Ding, S.Y.; Zhang, Y.B.; Wang, W. A dynamic three-dimensional covalent organic framework. J. Am. Chem. Soc. 2017, 139, 4995-4998. [CrossRef] [PubMed]

197. Li, H.; Pan, Q.; Ma, Y.; Guan, X.; Xue, M.; Fang, Q.; Yan, Y.; Valtchev, V.; Qiu, S. Three-dimensional covalent organic frameworks with dual linkages for bifunctional cascade catalysis. J. Am. Chem. Soc. 2016, 138, 14783-14788. [CrossRef] [PubMed] 